\title{
Helios, a T cell-restricted Ikaros family member that quantitatively associates with Ikaros at centromeric heterochromatin
}

\author{
Kyungmin Hahm, ${ }^{1,5}$ Bradley S. Cobb, ${ }^{1}$ Aaron S. McCarty, ${ }^{1}$ Karen E. Brown, ${ }^{2}$ Christopher A. Klug ${ }^{3,4}$ \\ Robert Lee, ${ }^{1}$ Koichi Akashi, ${ }^{3}$ Inving L. Weissman, ${ }^{3}$ Amanda G. Fisher, ${ }^{2}$ and Stephen T. Smale ${ }^{1,6}$ \\ ${ }^{1}$ Howard Hughes Medical Institute, Molecular Biology Institute, and Department of Microbiology and Immunology, UCLA \\ School of Medicine, Los Angeles, California 90095-1662 USA; ${ }^{2}$ Lymphocyte Development Group, M RC Clinical Sciences \\ Centre, Imperial College School of Medicine, Hammersmith Hospital, London, W12 ON N UK; ${ }^{3}$ Departments of Pathology \\ and Developmental Biology, Stanford University School of Medicine, Stanford, California 94305-5428 USA; ${ }^{4}$ Department of \\ Microbiology, University of Alabama, Birmingham, Alabama 35294 USA
}

The Ikaros gene encodes multiple protein isoforms that contribute critical functions during the development of Iymphocytes and other hematopoietic cell types. The intracellular functions of Ikaros are not known, although recent studies have shown that Ikaros proteins colocalize with inactive genes and centromeric heterochromatin. In this study, Ikaros proteins were found to be components of highly stable complexes. The complexes from an immature T cell line were purified, reveal ing associated proteins of 70 and $30 \mathrm{kD}$. The p70 gene, named H elios, encodes two protein isoforms with zinc finger domains exhibiting considerable homology to those within Ikaros proteins. Helios and Ikaros recognize similar DNA sequences and, when overexpressed, Helios associates indiscriminately with the various Ikaros isoforms. Although Ikaros is present in most hematopoietic cells, Helios was found primarily in T cells. The relevance of the Ikaros-Helios interaction in T cells is supported by the quantitative association of Helios with a fraction of the Ikaros. Interestingly, the Ikaros-Helios complexes localize to the centromeric regions of $T$ cell nuclei, similar to the Ikaros localization previously observed in B cells. Unlike the B cell results, however, only a fraction of the Ikaros, presumably the fraction associated with Helios, exhibited centromeric localization in $\mathrm{T}$ cells. These results establish immunoaffinity chromatography as a useful method for identifying Ikaros partners and suggest that Helios is a limiting regulatory subunit for I karos within centromeric heterochromatin.

[Key Words: Ikaros; Helios; T Iymphocyte; lymphocyte devel opment; heterochromatin]

Received December 8, 1997; revised version accepted January 22, 1998.

The molecular mechanisms by which B and T Iymphocytes are generated from hematopoi etic stem cells have been the subject of intensive investigation. By analysis of the immunoglobulin and $T$ cell receptor (TCR) gene recombination events and the differential expression of lymphocyte-specific genes, much has been learned about the regulation of $B$ and $T$ cell maturation (Clevers et al. 1993; Hagman and Grosschedl 1994; Ernst and Smale 1995; Clevers and Grosschedl 1996; Shortman and Wu 1996; Willerford et al. 1996). In contrast, little is known about the earliest stages of lymphocyte devel opment, including commitment to the lymphocyte lineages and the maturation events that precede gene recombination

\footnotetext{
5Present address: Howard Hughes Medical Institute, Children's Hospital, Harvard Medical School, Boston, Massachusetts 02115 USA.

Corresponding author.

E-MAIL steves@hhmi.ucla.edu; FAX (310) 206-8623.
}

(Ikuda et al. 1992; Morrison et al. 1995; Orkin 1995; Singh 1996; Georgopoulos et al. 1997).

In recent years, insight into the early regulatory events has been provided by the phenotypes of mice containing homozygous disruptions of genes encoding sequencespecific DN A-binding proteins (Orkin 1995; Clevers and Grosschedl 1996; Singh 1996; Ting et al. 1996; Georgopoulos et al. 1997). PU.1, Ikaros, E2A, EBF, BSAP, and GATA-3 are among the proteins that are critical for early lymphocyte development. Most of these proteins act as typical transcription factors, which bind to regulatory elements within specific target genes and direct gene activation.

Ikaros is unusual among the above DN A-binding proteins as none of its targets has been clearly established and its intracellular functions remain unknown. The Ikaros gene was first identified through an expression library screen for proteins that interact with an enhancer 
for the TCR CD $3 \delta$ gene (Georgopoul os et al. 1992). The gene was later found to encode the LyF-1 protein that interacts with a critical control element in the promoter for the lymphocyte-specific terminal transferase (TdT) gene (Lo et al. 1991; Hahm et al. 1994). Primary Ikaros transcripts undergo alternative premRNA splicing to generate several protein isoforms. The isoforms vary within an amino-terminal zinc finger domain that is responsible for sequence-specific DN A binding (Hahm et al. 1994; Molnar and Georgopoulos 1994; Molnar et al. 1996; Sun et al. 1996). The largest Ikaros isoform (isoform Vl; lk-1) contains four zinc fingers near the amino terminus, whereas the smaller isoforms contain fewer or no amino-terminal zinc fingers. All isoforms contain two additional zinc finger motifs at their carboxyl terminus, which do not bind DN A (Hahm et al. 1994), but serve as protein-protein interaction domains (Sun et al. 1996). Given the apparent indiscriminate nature of the protein-protein interactions, a large number of dimeric or multimeric species can be generated. Recently, a protein related to Ikaros was identifed by degenerate PCR with primers complementary to sequences encoding the carboxy-terminal zinc fingers (M organ et al. 1997). This protein, Aiolos, exhibits considerable homology to Ikaros and interacts with Ikaros through its carboxy-terminal fingers (M organ et al. 1997).

Ikaros isoforms are expressed in most cells of the hematopoietic lineages, including multipotent stem cells (Georgopoul os et al. 1992; Hahm et al. 1994; M ol nar and Georgopoulos 1994; M organ et al. 1997; Klug et al. 1998). $M$ any cell types express the two largest isoforms ( $V$ and $\mathrm{VI}$ ), but isoform expression patterns vary to some extent in a cell-specific manner. Aiolos is expressed in most of the cell types that express Ikaros, except the earliest hematopoi etic progenitors (M organ et al. 1997). Gene disruption experiments have demonstrated that the Ikaros proteins are critical for multiple hematopoietic events (Georgopoul os et al. 1994; Winandy et al. 1995; Wang et al. 1996). The most striking defect in I karos ${ }^{-1-}$ mice is the absence of B cells, natural killer cells, and some T lineage cells, including fetal-derived T cells and some $\gamma \delta$ T cells (Wang et al . 1996). I karos ${ }^{-1}-$ mice al so exhibit a biased distribution and expansion of $\mathrm{CD} 4^{+} \mathrm{T}$ cells and defects in other hematopoietic lineages (Wang et al. 1996). A second Ikaros gene disruption, which eliminates the DNA-binding domain, but al lows expression of smaller isoforms, results in a more severe lymphopoietic defect; these mice contain no B or T lymphocytes or any of the known B or T cell progenitors (Georgopoul os et al. 1994). Heterozygotes of these mice contain normal Iymphocyte phenotypes and numbers at birth, but rapidly develop lymphoproliferative disorders (Winandy et al. 1995).

Ikaros-binding sites have been identified in the promoters or enhancers of several genes (Lo et al. 1991; Georgopoulos et al. 1992; Omori and Wall 1993; Wargnier et al. 1995; Babichuk et al. 1996; Haag et al. 1996; Santee and Owen-Schaub 1996; Wang et al. 1996), but none of these genes has been shown to be an authentic Ikaros target. A well-characterized binding site for Ikaros within the TdT promoter is critical for promoter activity in immature lymphocytes (Lo et al. 1991). Ets family proteins al so bind this site however, and several findings suggest that the Ets protein Elf- 1 is the functional activator of TdT transcription (Ernst et al. 1993, 1996). Ikaros and Elf-1 cannot bind simul taneousl y to this el ement (K. Hahm, L. Trinh, P. Ernst, and S.T. Smale, in prep.), suggesting that if Ikaros contributes to TdT promoter activity, it does so as a repressor or competitive inhibitor of the Elf-1 activator.

Recent studies of subnuclear localization in B cells have provided further evidence that Ikaros may not be a simple transcriptional activator, as it was found by immunogold el ectron microscopy and confocal microscopy to local ize to heterochromatin (Brown et al. 1997; Klug et al. 1998). More specifically, by combining fluorescence in situ hybridization with confocal immunofluorescence assays, Ikaros colocalized with centromeric heterochromatin and with inactive genes, which themselves migrate to foci of centromeric heterochromatin (Brown et al. 1997).

The centromeric localization of Ikaros makes an understanding of its precise intracellular functions difficult to establish. The ability of the many Ikaros isoforms to associate with one another indiscriminately into a large number of dimeric or multimeric species adds further complexity, as each species may carry out a distinct function. Finally, the complicated phenotypes of the lka$\operatorname{ros}^{-1-}$ mice suggest that Ikaros proteins may carry out different functions in the different hematopoietic cell lineages, perhaps in association with lineage-restricted partners. As an essential step toward an understanding of these issues, we performed a biochemical analysis of the native Ikaros proteins. This analysis reveal ed that Ikaros proteins form highly stable complexes that can be purified to near homogeneity by immunoaffinity chromatography, providing a means of isolating Ikaros partners in various cell types. The Ikaros complexes purified from an immatureT cell line contain an Ikaros-associated protein, Helios, which possesses a zinc finger structure similar to that found in Ikaros. The restricted expression pattern of Helios, its presence at limiting quantities, its quantitative association with Ikaros, its assembly into a relatively homogeneous complex, and its specific localization to centromeres suggest that it functions as a critical regulator of Ikaros within the centromeric heterochromatin regions of the nucleus.

\section{Results}

Expression of I karos isoforms by RLm11 and VL3-3M2 T cells

For most of the studies described in this report, a murine radiation-induced thymoma cell line, RLm11, was employed. This cell line produces large quantities of TdT mRN A and protein and has been used for several years to study the transcriptional regulation of the TdT gene, a potential Ikaros target (Lo et al. 1991; Ernst et al. 1993, 1996; Hahm et al. 1994). Immunoblot and RT-PCR 
analyses have demonstrated that RLm11 cells actively express 4 of the 10 Ikaros isoforms (see Fig. 1, isoforms I, III, V, and VI; Hahm et al. 1994; M olnar and GeorgopouIos 1994; Sun et al. 1996). All four of these isoforms have been detected in populations of primary immature lymphocytes (Molnar and Georgopoulos 1994; M olnar et al. 1996; Klug et al. 1998).

For some experiments, another T cell line, VL3-3M 2, was used (Groves et al. 1995). This cell line expresses large quantities of the TdT, RAG-1, and RAG-2 mRN As and exhibits properties of double-positive $\mathrm{CD} 4^{+} \mathrm{CD} 8^{+}$ cells (Groves et al. 1995). VL3-3M 2 cells produce primarily two Ikaros isoforms, $V$ and VI (see Fig. 8, below), the two most abundant isoforms detected in primary thymocytes (data not shown; M ol nar and Georgopoulos 1994).

\section{I karos isoforms coelute in a broad peak from gel} fitration columns

Gel filtration chromatography was used to study the properties of the Ikaros proteins within RLml1 nuclear extracts. Immunoblot analysis of column fractions collected from a Superdex 200 FPLC column (Pharmacia) reveal ed that all four isoforms coelute in a broad peak between the excluded volume (exclusion limit, $1.3 \times 10^{6}$ kD) and a 232-kD molecular mass marker (Fig. 1, lanes 3-8). In contrast, Elf-1, with a cal culated molecular mass of 76 kD (Davis and Roussel 1996), eluted in a sharp peak at $\sim 200 \mathrm{kD}$ (Fig. 1A, lanes 8-10). When using a gel filtration column with a larger exclusion limit, the four Ikaros isoforms again coel uted with each other in a broad peak between 750 and 200 kD (data not shown; see Fig. 9, below). Similar results were obtained in several experi-

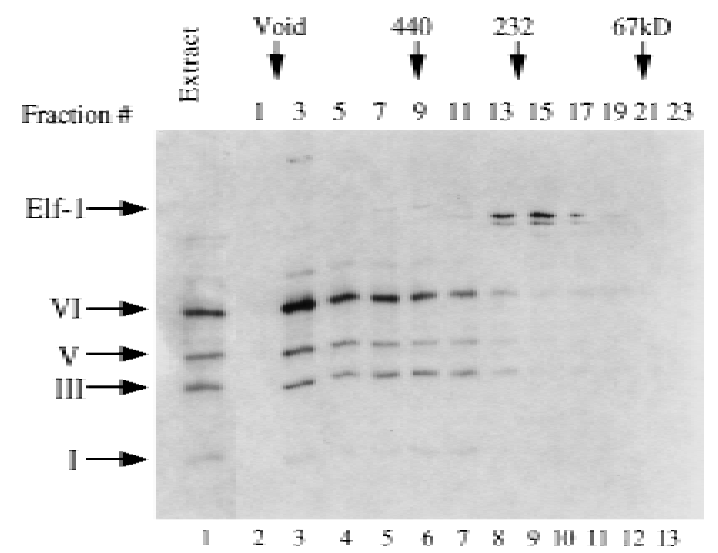

Figure 1. Coelution of Ikaros isoforms in a broad peak from gel filtration columns. RLm11 nuclear extracts (1 mg) were analyzed by Superdex 200 (Pharmacia) gel filtration chromatography. Five micrograms of nuclear extract (lane 1) and $45 \mu \mathrm{l}$ of every other column fraction (lanes 2-13) were separated by SDSPAGE and analyzed by immunoblotting, with antiserum directed against Ikaros and Elf-1. The fractions in which standard molecular mass markers elute are indicated by arrows at the top, and the bands corresponding to Elf-1 and Ikaros isoforms I, III, V, and VI are (left). ments with independent extract preparations and with column buffers at 0.1 and $0.45 \mathrm{M} \mathrm{KCl}$, both in the presence and absence of N P-40 detergent (data not shown).

The above results raise the possibility that Ikaros proteins form an array of multimeric complexes. The results of other biochemical experiments are consistent with the multimer hypothesis, but some results have suggested that the proteins exist as highly stable dimers (A.S. McCarty, K. Hahm, R. Lee, B.S. Cobb, unpubl.). Further experiments will be needed to clarify the precise stoichiometry of the Ikaros complexes, but for the purposes of this study, the relevant findings are: (1) Ikaros proteins appear to exist as stable dimeric or multimer complexes in solution, and (2) the unusually broad elution profile suggests that a given cell contains a large number of distinct complexes. This latter suggestion is consistent with previous studies in which the carboxyterminal zinc finger domains of Ikaros were found to promote indiscriminate protein-protein interactions between Ikaros isoforms (Sun et al. 1996; K. Hahm, unpubl.).

\section{Purification of I karos complexes}

To elucidate the intracellular functions of a protein, a critical objective is to identify other proteins with which it carries out relevant interactions. The biochemical properties summarized above and the complicated phenotypes of the 1 karos $^{-1-}$ mice raise the possibility that the Ikaros isoforms stably associate with proteins that have not been identified. Because of the apparent stability of the complexes, purification by immunoaffinity chromatography was an attractive method for identifying relevant Ikaros-associated proteins. Polyclonal antibodies directed against the carboxy-terminal half of Ikaros were initially used for the purification. RLm11 nuclear extracts in a buffer containing $0.45 \mathrm{M} \mathrm{KCl}$ were applied to a protein A-Sepharose column containing covalently linked antibodies (see $M$ aterials and $M$ ethods). The column was washed extensively with 0.45 and $1 \mathrm{M}$ $\mathrm{KCl}$ and, in some experiments, with $0 \mathrm{M} \mathrm{KCl}$ to disrupt nonspecific hydrophobic interactions. Tightly bound proteins were eluted with a buffer containing $100 \mathrm{~mm}$ trimethyl ethanolamine (pH 11.0). Analysis of the el uted proteins by SDS-PAGE followed by silver staining revealed six bands that were consistently observed at comparable molar amounts (Fig. 2A, lanes 3-6). Four of these bands correspond to Ikaros isoforms I, III, V, and VI, based on immunoblot analysis with Ikaros antibodies (lane 7). The other two bands, which migrate at 30 and 70 kD (p30 and p70, respectively), did not interact with the Ikaros antibodies by immunoblot analysis. These proteins also did not cross-react with three Ikaros antisera raised against other domains of the Ikaros isoforms (data not shown). These results suggest that p30 and p70 bound to the column through specific interactions with Ikaros proteins.

Although denatured p30 and p70 did not interact with the Ikaros antibodies by immunoblot analysis, it remained possible that they copurified with Ikaros because 

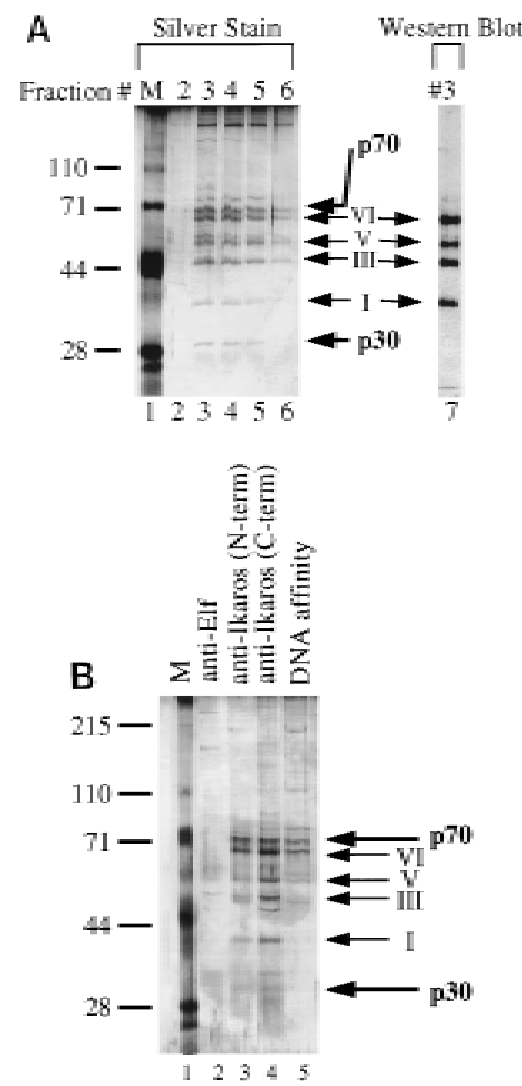

Figure 2. Immunoaffinity purification of Ikaros complexes from RLm11 nucl ear extracts. (A) RLm11 nuclear extracts were applied to a protein A-Sepharose column containing coval ently linked antibodies directed against the carboxy-terminal half of Ikaros (see Materials and Methods). After washing the resin with buffers containing 0.45 and $1 \mathrm{M} \mathrm{KCl}$, bound proteins were eluted with $100 \mathrm{~mm}$ trimethyl ethanolamine (pH 11.0). The trimethyl ethanol amine fractions (numbers 2 through 6, lanes 2-6) were analyzed by SDS-PAGE followed by silver staining. Molecular mass markers are shown in lane 1 and are indicated to the left. Fraction 3 was also analyzed by immunoblotting with anti-Ikaros serum (lane 7). Ikaros isoforms I, III, V, and VI are indicated between lanes 6 and 7. Two proteins, p30 and p70, were detected by silver staining that did not interact with the Ikaros antibodies. (B) RLm11 extracts were applied to protein A-Sepharose columns containing covalently linked antibodies directed against Elf-1 (lane 2), the carboxyl-terminus of Ikaros (lane 3), or the amino-terminus of Ikaros (lane 4). The columns were washed and proteins el uted as described above. Portions of the trimethyl ethanolamine eluates were analyzed by SDSPAGE followed by silver-staining. Also analyzed were proteins purified by sequence-specific DNA-affinity chromatography with a resin containing coval ently linked multimers of the TdT D element (lane 5, see $\mathrm{M}$ aterials and $\mathrm{M}$ ethods and $\mathrm{H}$ ahm et al. 1994). Molecular mass markers are shown in lane 1 and are indicated at left in KD. Ikaros isoforms I, III, V, and VI, p70, and p30, are indicated at right.

they were recognized in their native conformations by the anti bodies. To address this possibility, immunoaffinity chromatography was performed with a resin containing an antibody preparation directed against an aminoterminal domain of Ikaros (Fig. 2B, lanes 3,4). The p70 and $\mathrm{p} 30$ proteins bound to this resin as efficiently as to the carboxy-terminal antibody resin. In contrast, an immunoaffinity resin containing an unrelated antibody preparation of similar titer, directed against murine Elf1, did not yield detectable proteins of 30 and 70 kD (Fig. 2B, lane 2).

As a final control, Ikaros was purified by DN A-affinity chromatography with a resin containing covalently linked multimers of the TdT D element, which comprises an Ikaros-binding site (Lo et al. 1991). The DNAaffinity chromatography procedure was an improved version of the procedure used previously to purify and cl one Ikaros (Hahm et al. 1994). In the previous experiments, only a single 65-kD band was observed. This band contained a mixture of Ikaros isoform VI and YY 1 , which also binds to a sequence within the $D$ element (see Hahm et al. 1994). In the new experiment, which diminished YY 1 copurification, Ikaros isoforms III, V, VI, and the p70 protein, were readily detected (Fig. 2B, lane 5). Ikaros isoform I and p30 were less apparent and possibly less abundant, but were detected in some experiments (data not shown).

\section{Isolation of Helios}

To isolate the gene encoding p70, the immunoaffinity purification procedure was carried out with large quantities of RLmll extract (see M aterials and M ethods). The purified fractions were then concentrated and the proteins separated on a preparative SDS-polyacrylamide gel. After transferring to a PVDF membrane, the p70 band was excised, proteolyzed with endopeptidase $C$, and sequences of two peptides were obtained (Fernandez et al. 1994). The peptide sequences (see Fig. 3) were unrelated to proteins or genes described in various databases (data not shown).

Degenerate oligonucleotides were used to isolate a 216-bp fragment of the p70 gene by RT-PCR from RLm11 mRNA. A full-length CDNA was then isolated from a library prepared from newborn mouse thymus mRN A (Stratagene). Subsequent studies revealed two distinct CDNA products, p70A and p70B, that presumably are generated by alternative premRNA splicing. RT-PCR analysis of RLm11 mRN A revealed that the two RNA products are present at comparable amounts (data not shown).

DNA sequencing of the $p 70 A$ and $p 70 B$ CDNAs revealed 1500- and 1578-bp ORFs, respectively, encoding proteins of 55 and $58 \mathrm{kD}$ (Fig. 3). The proteins contain domains with considerable homology to domains within Ikaros. Because of this homology, we named the p70 gene Helios. The small sizes of the Helios proteins relative to their apparent molecular masses based on SDSPAGE are consistent with the properties of the Ikaros proteins; the calculated molecular mass of Ikaros isoform $\mathrm{VI}$, for example, is $57 \mathrm{kD}$, whereas its apparent molecular mass by SDS-PAGE is $65 \mathrm{kD}$. The most striking homology between Helios and Ikaros is within the amino- and carboxy-terminal zinc finger domains. $\mathrm{He}$ lios A (which lacks the lower-case amino acids in Fig. 3) 
Figure 3. Helios A and Helios B contain zinc fingers with homology to those in Ikaros and Aiolos. An amino acid sequence alignment compiled by use of the PILEUP program is shown. Compared are the largest isoforms of the Ikaros family members, Helios B, Ikaros isoform VI (Ik-1), and Aiolos. Lowercase lettering in the $\mathrm{Hel}$ ios $\mathrm{B}$ sequence designates the sole difference between $\mathrm{Helios} B$ and Helios A. Amino acid sequences obtained by microsequencing of purified Helios protein are indicated by a line above the Helios sequence. Shaded boxes in blue emphasize the highly conserved zinc finger motifs. Yellow bars indicate the conserved cysteines and histidines in the zinc fingers. The red box indicates the unusual cysteine in the apparent $\mathrm{C}_{2} \mathrm{HC}$ finger. Overall sequence similarities are as follows: Helios B-Ikaros, 55\%; Ikaros-Aiolos, 53\%; Helios B-AioIos, $50 \%$. The four amino-terminal zinc fingers of Helios share $94 \%$ identity with the Ikaros fingers and the Aiolos fingers share $86 \%$ identity with the Ikaros fingers. The two carboxy-terminal zinc fingers of Helios share $85 \%$ identity with the corresponding Ikaros fingers, with $80 \%$ identity between the Aiolos and Ikaros fingers. The Helios CDNA and amino acid sequences have been deposited in the GenBank/Swiss Prot databases (accession nos. AF044257 and P81183, respectively).

contains two $\mathrm{C}_{2} \mathrm{H}_{2}$ zinc fingers (yellow) and one $\mathrm{C}_{2} \mathrm{HC}$ zinc finger (red) near its amino terminus, similar to lkaros isoform $\mathrm{V}$. Helios $\mathrm{B}$ (which contains the lower-case amino acids in Fig. 3) contains three $\mathrm{C}_{2} \mathrm{H}_{2}$ zinc fingers and one $\mathrm{C}_{2} \mathrm{HC}$ zinc finger near its amino terminus, similar to Ikaros isoform VI. Both Helios isoforms, like all of the Ikaros isoforms, contain two carboxy-terminal zinc finger motifs (yellow). The Helios and Ikaros zinc finger domains are highly homologous at the amino acid level. Surrounding the two zinc finger domains, a few short stretches of identity and similarity between Helios and Ikaros are apparent, but most of the Helios sequence exhibits little homology to Ikaros.

Recently, another protein with zinc finger domains

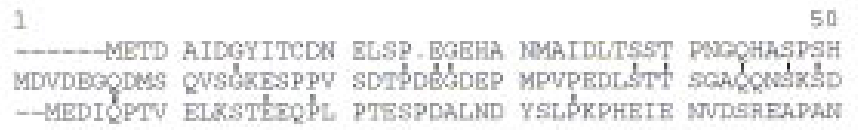

51

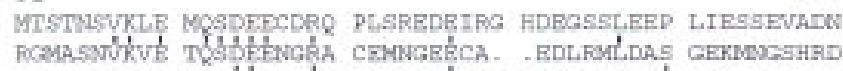

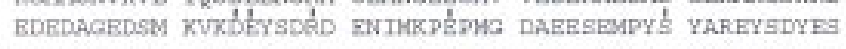
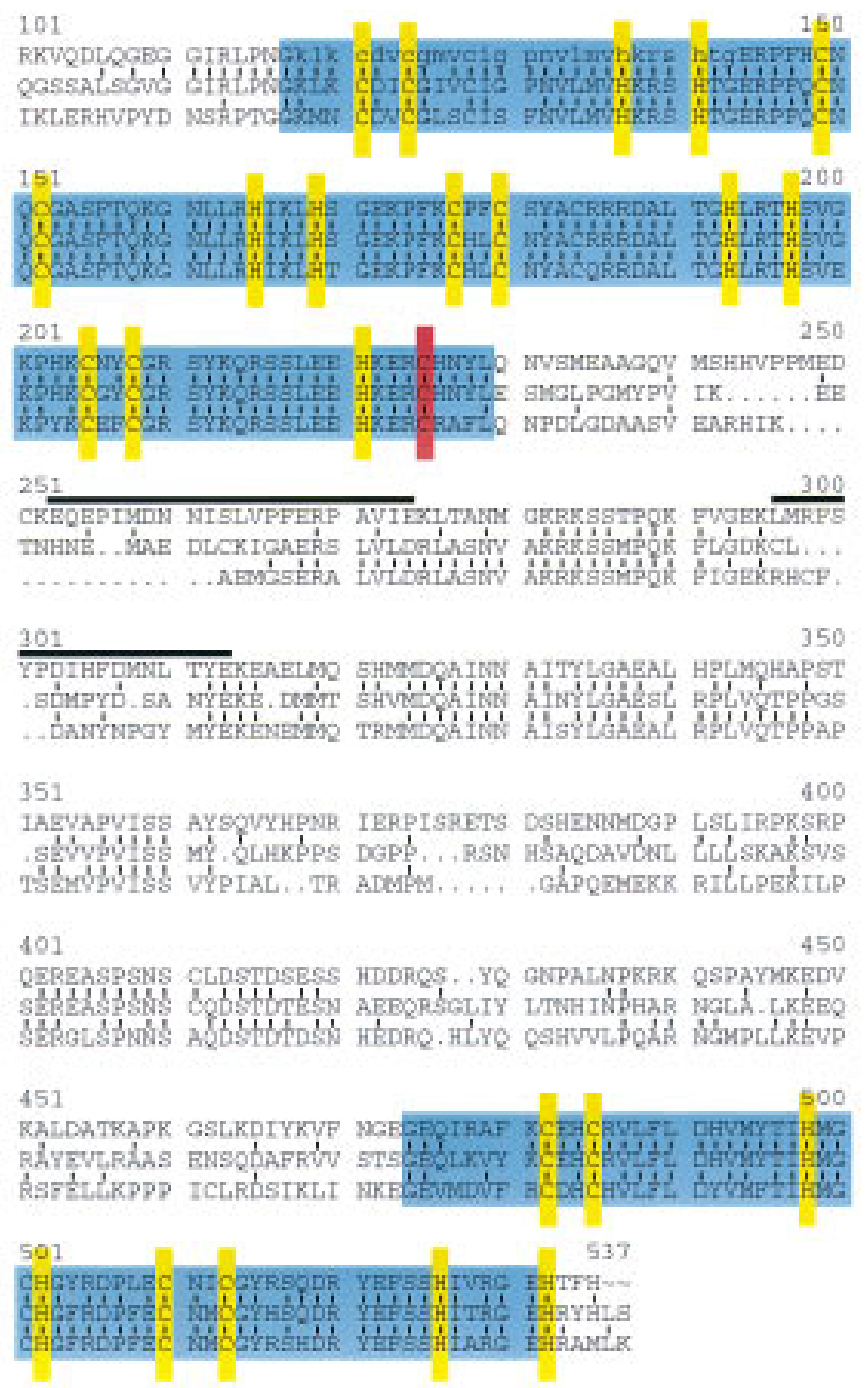

homologous to Ikaros, called Aiolos, was isolated from a cDNA library by PCR with degenerate primers directed against the carboxy-terminal zinc-finger domain of Ikaros (Morgan et al. 1997). The Ikaros, Aiolos, and Helios zinc finger domains are highly homologous to each other (Fig. 3). The stretches of Ikaros-Helios homology surrounding the zinc finger domains are also homologous to Aiolos (e.g., amino acids 282-295 and 312-362).

The isolated Helios gene appears to encode the protein purified by immunoaffinity chromatography on the basis of two criteria: First, both peptide sequences obtained from the purified protein are encoded by the Helios gene (Fig. 3, overlined). Second, immunoblot analysis of the purified protein with antibodies generated against the 
amino-terminal 109 amino acids of Helios, reacted strongly with a protein of the expected size (Fig. 4A).

Specific, indiscriminate protein-protein interactions between Helios and I karos isoforms

The above data suggest that Helios copurifies with Ikaros by immunoaffinity chromatography because the two proteins are tightly associated with each other in RLm11 cells. To confirm that recombinant Helios can interact with recombinant Ikaros isoforms, an expression vector for Helios A containing a FLAG epitope tag was cotransfected into 293T cells al ong with expression vectors for Ikaros isoforms I, V, and/or VI. Interactions were monitored by immunoprecipitation with anti-FLAG antibodies, followed by immunoblot analysis with either Ikaros or Helios antibodies. Figure 4B shows the Helios A and Ikaros proteins in 293T cytoplasmic and nuclear extracts prior to immunoprecipitation. (Ikaros and Helios antibodies were added to the immunoblot to visualize the products of both genes, but the relative amounts of the Ikaros and Helios gene products cannot be determined from these data.) Epitope-tagged Helios A localized to the nucl eus and migrated slightly slower than Ikaros isoform VI (e.g., Fig. 4B, lane 14), agreeing with the migration pattern of Helios observed in the purified complexes. Immunoprecipitation with FLAG antibodies (Fig. $4 C$ ) reveal ed that FLAG-Helios A interacts with all three
Ikaros isoforms with similar efficiencies (on the basis of a comparison on the relative protein amounts before and after immunoprecipitation). The carboxy-terminal zinc fingers are likely to be responsible for the interactions, given the strong homology between the Ikaros and Helios domains.

\section{DNA-binding-site specificity of Helios A}

The above results suggest that intracellular complexes exist containing a combination of Helios and Ikaros proteins. Helios complexes may also exist without Ikaros components, and Ikaros complexes may exist without Helios components. Perhaps, the various complexes carry out different functions by recognizing different DN A sequences. To determine the DN A sequence specificity of Helios A, a binding-site selection-PCR ampification strategy was employed with a fusion protein containing the Helios A DNA-binding domain and GST (Zweidler-McKay et al. 1996; see Materials and Methods).

The selected clones revealed potential recognition se quences that can be divided into two groups (Fig. 5A). The first group, containing 19 sequences, was characterized by the core sequence GGGA. The second group, containing 30 sequences, was characterized by the core sequence GGAAAA. A simple interpretation of these data is that the core sequence GGA is generally suffi-

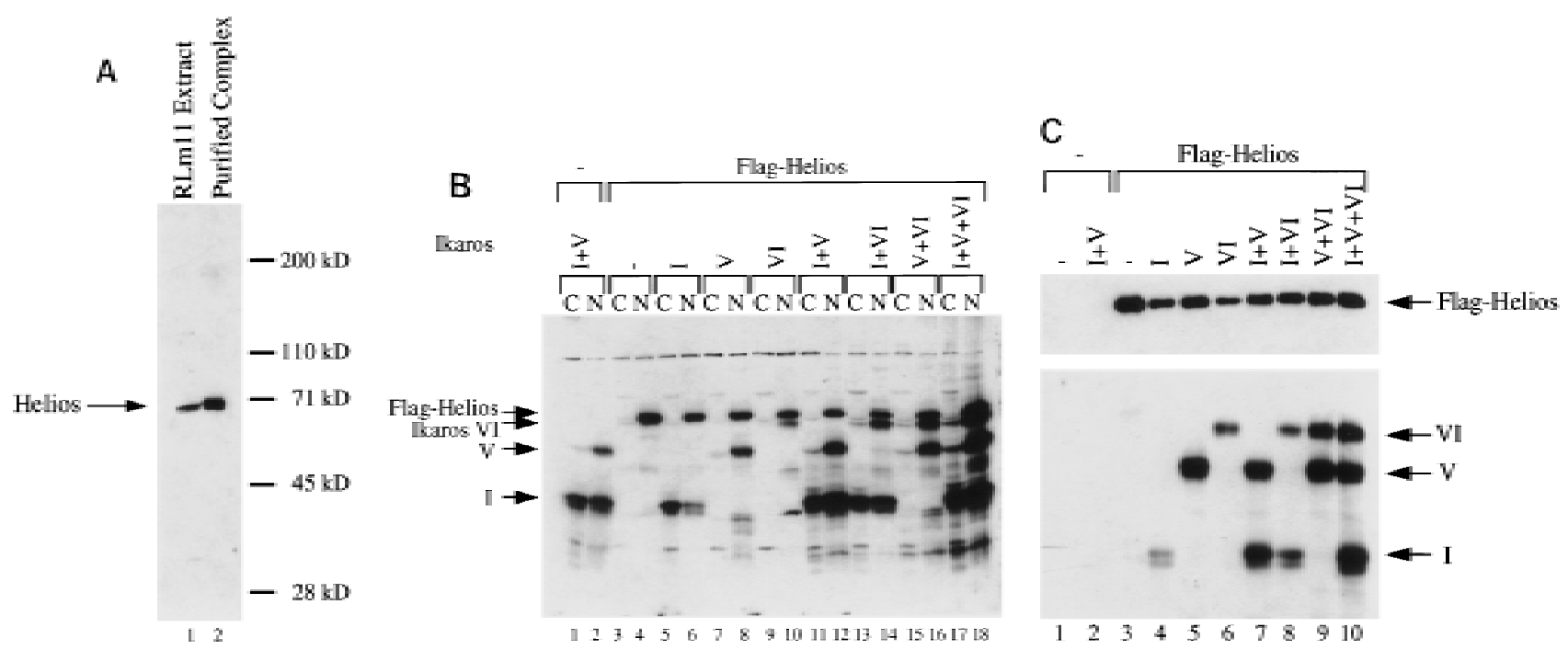

Figure 4. Indiscriminate interactions between Helios A and Ikaros isoforms in 293T cells. (A) The Helios protein within an RLm11 extract (lane 1) and the immunoaffinity purified Ikaros complex (lane 2) can be detected by immunoblot analysis with antisera directed against recombinant Helios (amino acids 1-109). M olecular mass markers are indicated at right, and the location of the Helios band is indicated at left. (B) 293T cells were transfected with 10 or $15 \mu \mathrm{g}$ of expression plasmids for various Ikaros isoforms (lanes 1-18; specific isoforms indicated above each lane), in the absence (lanes 1,2) or presence (lanes 3-18) of an expression plasmid for FLAGtagged Helios A (5 $\mu \mathrm{g})$. Cytoplasmic (odd-numbered lanes) and nuclear (even numbered lanes) extracts from the transfected cells were analyzed by immunoblotting with anti bodies di rected against both Helios and Ikaros. The bands corresponding to FLAG-tagged Helios A and Ikaros isoforms I, V, and VI are indicated to the left. (C) Interactions between Helios A and Ikaros isoforms were assessed by immunoprecipitation from the nuclear extracts shown in part B with a monoclonal antibody directed against the FLAG epitope. Proteins within the immunoprecipitated pellet were analyzed by immunoblotting with antisera directed against Helios (top) or Ikaros (bottom). The extacts used for immunoprecipitation contained (lanes 3-10) or lacked (lanes 1,2) the FLAG-Helios A protein and zero, one, two, or three Ikaros isoforms (isoforms indicated above each lane). The locations of the bands corresponding to FLAG-Helios A and Ikaros isoforms I, V, and VI are indicated to the right. 


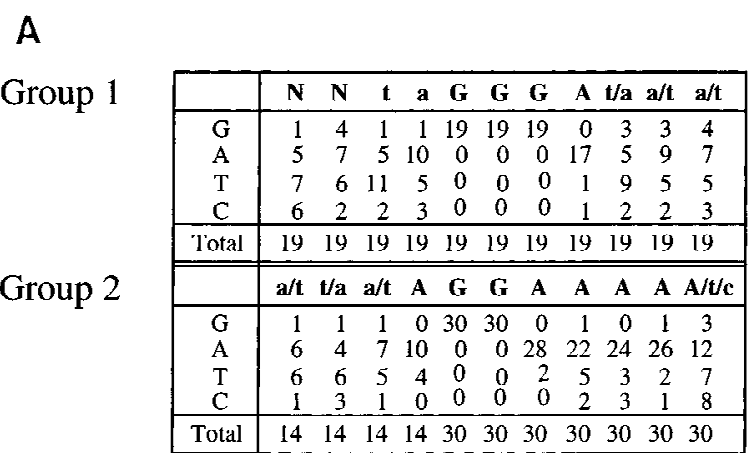

Figure 5. Helios $A$ and Ikaros isoform $V$ bind to similar DNA sequences. (A) High-affinity Helios A-binding sites were selected by a GST pull-down assay (Zweidler-M cKay et al. 1996). DN A fragments selected by the GST-Helios A fusion protein were sequenced and tabulated. The selected sequences can be divided into two groups, both containing a core sequence of GGA. Group 1 was represented by 19 sequences and Group 2, by 30 sequences. The number of fragments containing each nucleotide at a given position following alignment are indicated for each group. Only 14 sequences are shown for the first four positions of the Group 2 sequence because the remaining 16 were derived from fragments in which these four positions were contained within the invariant primer-binding sites flanking the variable sequences. (B) Gel mobility shift assays were performed with recombinant GST-Ikaros isoform V (lanes 1-6) and recombinant Helios A (lanes 7-12) with probes containing the five sequences shown at the bottom (lanes 2-6, 8-12) and a negative control probe (lanes 1,7). The specific probes were derived from the pSP72 (Promega) multiple cloning site region (lanes 1,7), the TdT D (lanes 2,8) and D' (Ianes 3,9) el ements, the Hs BS1 (i.e., Helios binding site 1; lanes 4,10) and Hs BS2 (lanes 5,11) sequences selected in this study, and the IkBS2 (lanes 6,12) sequence sel ected previously (M ol nar and Georgopoul os 1994).

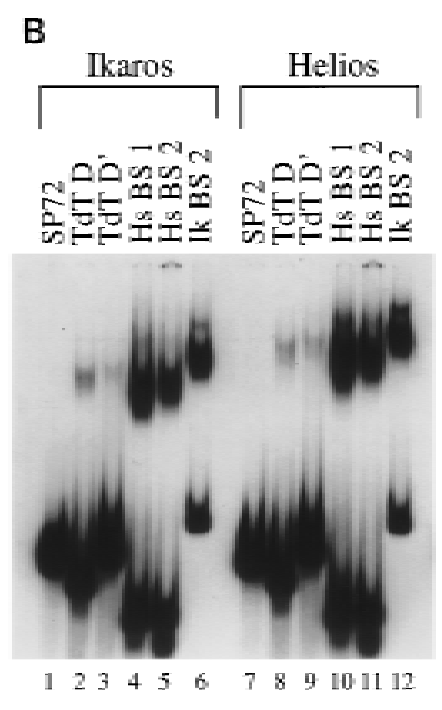

TdT D : TTTGGGAGA

Hs BS1 : ATCCATAGGGAAAATTATCCTAG

Hs BS2 : AGGATTCTCATTAGGAAAATCCA

Ik BS2 : TTTTGGGAATCTCCTGTCA
TdT D' : GACATTCCTTCAGCAGGAAGTTGT cient for high-affinity DNA binding if it is flanked by a guanine at the $5^{\prime}$ end or by three adenines at the $3^{\prime}$ end. The first group is very similar to a previously described consensus sequence for Ikaros isoform $\mathrm{V}$ ( $\mathrm{M}$ olnar and Georgopoulos 1994), which is the most homologous to Helios A. The second group did not match the Ikaros consensus sequence.

To determine whether the two groups of Helios A consensus sequences provide a functional distinction between Ikaros and Helios, gel mobility shift assays were performed with a probe representative of the first group (Fig. 5B, lanes 6,12; Ik BS2; Molnar and Georgopoulos 1994), a probe representative of the second group (lanes 5,11; Hs BS2), and a probe containing a sequence that conforms to both groups (lanes 4,10; Hs BS1). A negative control was also included (lanes 1,7$)$, along with probes containing two TdT promoter elements that are known to bind Ikaros (lanes 2,3,8,9). The results demonstrate that Ikaros isoform $\mathrm{V}$ and Helios $\mathrm{A}$ possess very similar sequence specificities, as the relative complex abundances observed with each probe were very similar for the two proteins. Thus, if Ikaros-Helios complexes carry out different functions from either Ikaros-Ikaros or $\mathrm{He}$ lios-Helios complexes, they are likely to do so as a result of other functional differences between Helios and Ikaros.

\section{T cell-restricted expression pattern of Helios}

To determine the expression pattern of Helios, $\mathrm{N}$ orthern blots were carried out with mRN A from transformed cell lines and murine tissues. Surprisingly, Helios mRNA was largely restricted to the $\mathrm{T}$ cell lineage. Four major transcripts were readily detected in three of four $T$ cell lines tested (Fig. 6A, lanes 3-6) and in a cell line containing early progenitors of multiple hematopoietic lineages (lane 2; T sai et al. 1994). No expression was observed in B lineage cell lines (lanes 7-9) or in fibroblast (lane 1) or macrophage (lane 10) lines. In contrast, the I karos gene was expressed at high levels in all three $B$ cell lines and at lower levels in the macrophage line (data not shown). Consistent with the expression pattern in the cell lines, abundant Heli os transcripts were detected in the thymus (lane 16), with very little expression in the bone marrow (lane 17) and brain (lane 11), and no detectabl e expression in spleen, liver, kidney, or muscle (lanes 12-15). By contrast, I karos transcripts were readily detected in both the spleen and thymus (Georgopoulos et al. 1992; data not shown). The reason for the existence of transcripts of different sizes has not been explored, but all four transcripts were detected when the blots were probed with gene fragments encoding amino acids 221-292 (Fig. 6A) or amino acids 1-109 (data not shown).

Immunobl ot experiments provided evidence that the Helios protein is restricted to the $T$ cell lineage (Fig. 6B). The expected 70-kD band was observed in four different T cell lines (Fig. 6B, lanes 2-6), but not in 5 cell lines of the $B$ lineage (lanes 7-11) or in erythroid (lane 12), macrophage (lane 13), or fibroblast (lane 14) lines. The T cellrestricted expression pattern of Helios is in striking contrast to the expression pattern of the Ikaros proteins, 
A
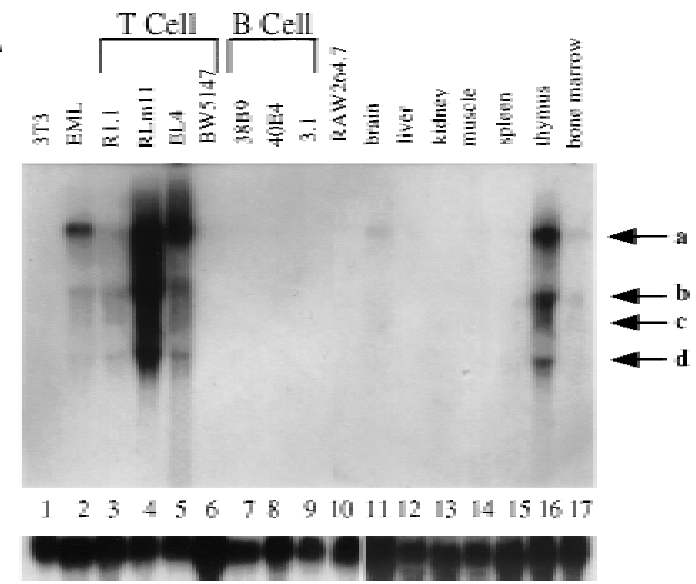

B

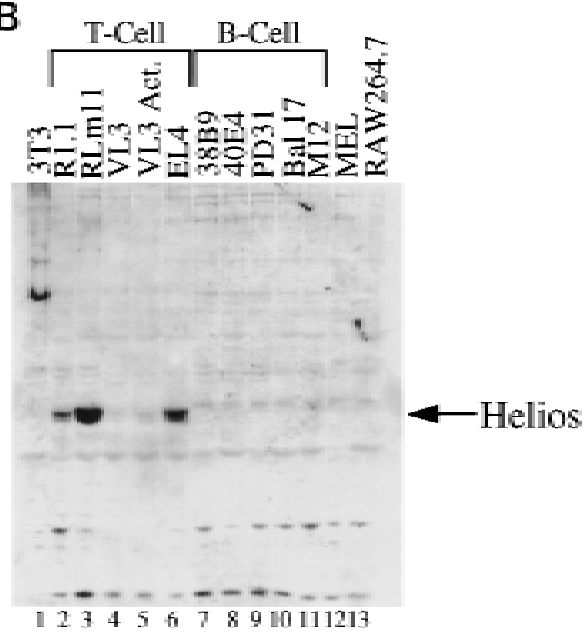

C

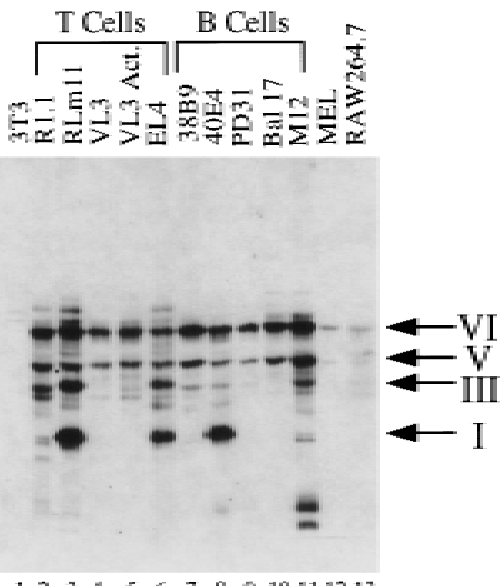

Figure 6. Helios expression is largely restricted in T cells. (A) N orthern bl ot analysis was used to measure Helios mRN A expression in murine hematopoietic cell lines and tissues. Cell lines and tissues analyzed are indicated at the top. Twenty micrograms of total RN As was analyzed in each lane. N itrocellulose membranes were hybridized sequentially with a Helios probe (fragment encoding amino acids 221-292, top) and a human $\beta$-actin probe (500 bp, bottom). Positions of the $28 \mathrm{~S}$ and $18 \mathrm{~S}$ rRN As are indicated. Actin transcripts and four major transcripts detected by $\mathrm{He}$ lios probe are indicated. (B) Helios protein in murine cell lines was analyzed by immunoblotting. Cell lines analyzed are indicated at the top. Twenty micrograms of protein from nuclear extracts estimated by Coomassie Assay (Pierce) were loaded in each lane. (p70) Protein migrating close to $70 \mathrm{kD}$ and detected with anti-Helios serum. (C) The nuclear extracts analyzed in $B$ were probes with antibodies directed against the carboxy-terminal half of Ikaros. which were present in all of the hematopoietic cell lines (Fig. 6C).

To examine Helios expression during $\mathrm{T}$ cell development, primary thymocytes were sorted by FACS into triple negative (CD3-4-8 ), double-positive $\left(\mathrm{CD}^{+} 4^{+} 8^{+}\right)$, and $\mathrm{CD}^{+}$single-positive $\left(\mathrm{CD}^{+} 4^{+} 8\right)$ populations (see $M$ aterials and $M$ ethods and Klug et al . 1998). Five different samples of 20 cells each were analyzed by RT-PCR for each population. PCR products were efficiently am- plified in four of five samples of tripl enegative cells (Fig. 7, Ianes 1-5), three of five samples of double-positive cells (lanes 7-11), and only one of five samples of singlepositive cells (lanes 13-17). DNA sequencing of the PCR products confirmed that they contain Helios sequences. The sequences also revealed that the small size difference between the products in lanes 2 and 3 versus 4 and 5 was attributable to the amplification of the Helios $A$ sequence in lanes 2 and 3 and the Helios $B$ sequence in

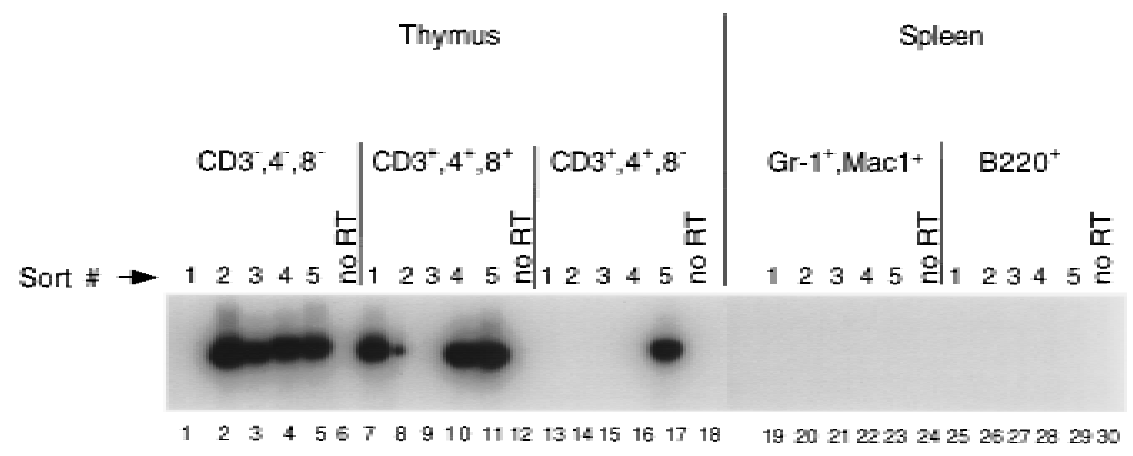

Figure 7. Helios expression in thymocyte and splenic cell subsets. Twenty cells of the indicated cell-surface phenotypes were sorted by FACS for analysis of Helios expression during thymocyte maturation and in non-T-lineage cell subsets. Primers for nested PCR amplified across sequences that encode the four amino-terminal zinc fingers of Helios. The PCR products observed with the various samples exhibit slightly different migrations, which represent the amplification of both the Helios A and Helios B products with predicted sizes of 712 and 790 bp, respectively. 
lanes 4 and 5 (data not shown). No PCR products were amplified from primary splenic neutrophils (Gr$1^{+} \mathrm{M} \mathrm{acl}^{+}$, lanes 19-23) or splenic B cells (B220 ${ }^{+}$, lanes 25-29). These results confirm the $T$ cell-restricted expression of Helios and suggest that it might be most abundant in immature cells of the $\mathrm{T}$ lineage.

\section{Quantitative association of Helios with Ikaros}

The stability of the Ikaros-Helios interaction provides strong evidence that the interaction is rel evant. To determine the percentage of Hel ios that is stably associated with Ikaros and, conversely, the percentage of Ikaros that is stably associated with Helios, quantitative immunoprecipitation experiments were performed with VL33M 2 (Fig. 8) and RLm11 (data not shown) cell extracts.

The immunoprecipitation reactions were carried out with increasing amounts of either Ikaros antibodies (lanes 2-5, 11-14) or Helios anti bodies (lanes 6-9, 15-18). The amounts of Ikaros and Helios within the immunoprecipitation pellets (lanes 1-9) and supernatants (lanes 10-18) were determined by immunobl ot anal ysis. Ikaros antibodies were capable of depleting almost all of the Helios from the VL3-3M 2 extracts, as determined by the depletion of almost all of the Helios from the immunoprecipitation supernatants (lanes 10-14, top). This result suggests that virtually all of the Helios within the cell is associated with Ikaros isoforms. In contrast, Helios antibodies depleted only a small fraction of the Ikaros (lanes 15-18, bottom), despite the ability of these antibodies to deplete all of the Helios (lanes 15-18, top). This result suggests that only a fraction of the lkaros is asso-

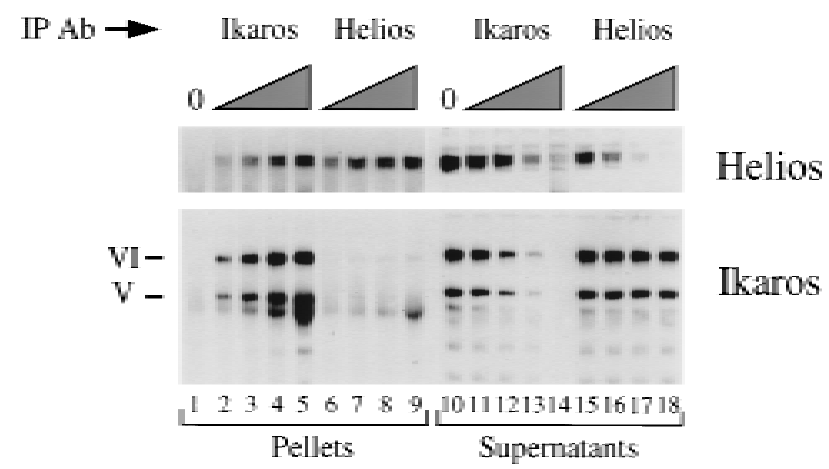

Figure 8. Quantitative association of Helios with a subset of the Ikaros within VL3-3M 2 cells. Quantitative immunoprecipitation experiments were performed with purified IgG directed against the amino-terminal domains of either Ikaros (lanes 25,11-14) or Helios (lanes 6-9,15-18). Control immunoprecipitations contained no added antibody (lanes 1,10). The proteins present in the immunoprecipitation pellets (lanes 1-9) and supernatants (lanes 10-18) were analyzed by immunoblot, with the membranes probed with antibodies directed against either Helios (top) or Ikaros (bottom). The two isoforms predominantly expressed in VL3-3M 2 cells are indicated to the left of the bottom panel. The amounts of anti-Ikaros or anti-Helios IgGs used in the immunoprecipitations were as follows: $1.5 \mu \mathrm{g}$ (lanes 2,6,11,15), $4.5 \mu \mathrm{gg}$ (lanes 3,7,12,16), $15 \mu \mathrm{g}$ (lanes $4,8,13,17)$, and $45 \mu \mathrm{g}$ (lanes $5,9,14,18)$.

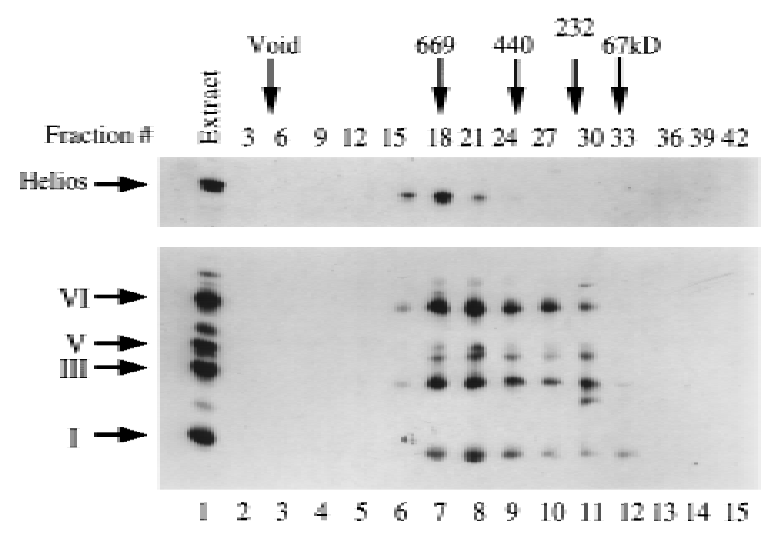

Figure 9. The Ikaros-Helios complexes appear to be relatively homogeneous when analyzed by gel-filtration chromatography. Proteins in Superose 6 (Pharmacia) gel-filtration column fractions were separated by $10 \%$ SDS-PAGE and analyzed by Western blot analysis involving probing of the bl ot sequentially with anti-Helios serum (top) followed by anti-lkaros serum (bottom). Four micrograms of RLm11 nuclear extracts was also analyzed (lane 1). The fractions where standard molecular mass markers migrate in Superose 6 (Pharmacia) gel-filtration chromatography are indicated by arrows on the top with their molecular masses. Isoforms I, III, V and VI are indicated.

ciated with Helios, and therefore that Ikaros is in considerable excess. Similar results were obtained with RLm11 extracts (data not shown). The quantitative association of Helios with Ikaros provides strong support for the functional relevance of the Ikaros-Helios interaction.

Helios and Ikaros exist as a relatively homogeneous complex

The overexpression experiments in 293T cells suggest that the four Ikaros isoforms and two Helios isoforms present in RLm11 cells are capable of forming stable complexes with each other in an indiscriminate manner. With six different proteins interacting through highly homologous carboxy-terminal zinc finger domains, 21 different dimers could be produced. If these dimers associate into multimers, as suggested by some of the data, a much larger number of species is possible. Each species might carry out a distinct function within the cell, or many of the complexes might carry out redundant functions. Alternatively, the interactions between the endogenous proteins in RLmll cells might not be as indiscriminate as suggested by the $293 \mathrm{~T}$ experiments. The relative elution profiles of Ikaros and Helios from a gel filtration column support this latter hypothesis (Fig. 9). As shown above (Fig. 1), Ikaros isoforms el ute from gel filtration columns in a broad peak and at large molecular masses. It is not known whether this el ution profile accurately reflects the sizes of the complexes, but the broad peak suggests that the complexes are quite heterogeneous. Surprisingly, Helios eluted as a sharp peak from a Superose 6 gel filtration column, coeluting with the largest of the Ikaros complexes (Fig. 9, lanes 6-8). 
This sharp elution profile suggests that Helios is not assembled into the same heterogeneous array of compl exes as I karos, but rather is assembled into one di screte complex, or at least a much more homogeneous set of complexes than Ikaros.

The gel filtration result raises the possibility that $\mathrm{He}$ lios is a limiting regulatory molecule that dictates the function of Ikaros isoforms. The apparently homogeneous complex containing Helios and Ikaros might carry out a specific function. The excess Ikaros that is not associated with Helios might assemble into specific complexes with other Ikaros-related proteins, such as the p30 protein (Fig. 2A). Indeed, a partial peptide sequence of p30 has revealed that it is another member of the Ikaros family (B.S. Cobb, unpubl.). Some of the excess Ikaros might instead exist as partially formed complexes that lack subunits essential for function.

Selective association of complexes containing Helios with centromeric regions of $\mathrm{T}$ cell nuclei

A recent study revealed that Ikaros might not be a typical transcriptional activator, as it was found in B cells to localize primarily to centromeric heterochromatin (Brown et al. 1997). This study also revealed that a variety of inactive genes colocalize with Ikaros to the centromeric regions, leading to the hypothesis that Ikaros might play a role in recruiting genes to centromeric foci that are destined for inactivation. Consistent with the hypothesis that both Helios and Ikaros are not typical transcriptional activators, we were unable to detect activation of reporter constructs containing multiple highaffinity Ikaros/Helios binding sites when various Ikaros and/or Helios isoforms were overexpressed (data not shown). In addition, none of these proteins appears to function as a simple transcriptional repressor in either transient or stable transfection experiments (data not shown).

Confocal microscopy was employed to examine whether the subnucl ear local ization of Helios and Ikaros in T cells is similar to the centromeric localization of Ikaros observed in B cells (Brown et al. 1997). For these experiments, VL3-3M2 and primary activated lymph node $T$ cells were used. Surprisingly, with both $T$ cell sources, Ikaros was distributed throughout the nucleoplasm and did not exhibit the predominant centromeric localization that had been observed in B cells. These results are apparent in Figure $10(\mathrm{~g}, \mathrm{~h}, \mathrm{i})$, which shows a single optical section of a representative lymph node $T$ cell stained with an Ikaros antibody (h) and with a fluorescent DNA probe for gamma satellite repeats (g), which are found primarily at centromeric regions of chromosomes (see M aterials and M ethods and Brown et al. 1997). The costained image (i) reveals patches of Ikaros staining at the edges of the centromeric foci (yellow), but most of the Ikaros was distributed throughout the nucleoplasm (green). Similar results were observed in VL3-3M 2 cells (data not shown). These results are in striking contrast to the results observed in B cells $(j, k, I)$, in which the Ikaros (j) and gamma-satellite (k) staining patterns are very similar to each other, and closely coincide in the costained image $(\mathrm{I})$.

Interestingly, in both the lymph node $\mathrm{T}$ cells $(\mathrm{a}, \mathrm{b}, \mathrm{c})$ and the VL3-3M 2 T cells (d,e,f), Helios colocalized with the gamma satellites at the centromeric foci, similar to the predominant localization of Ikaros in B cells. The colocalization is apparent by comparison of the gammasatellite staining pattern $(a, d)$ with the Helios staining pattern $(b, e)$ and by examination of the costained images $(b, e)$, in which colocalization is evident by the orange
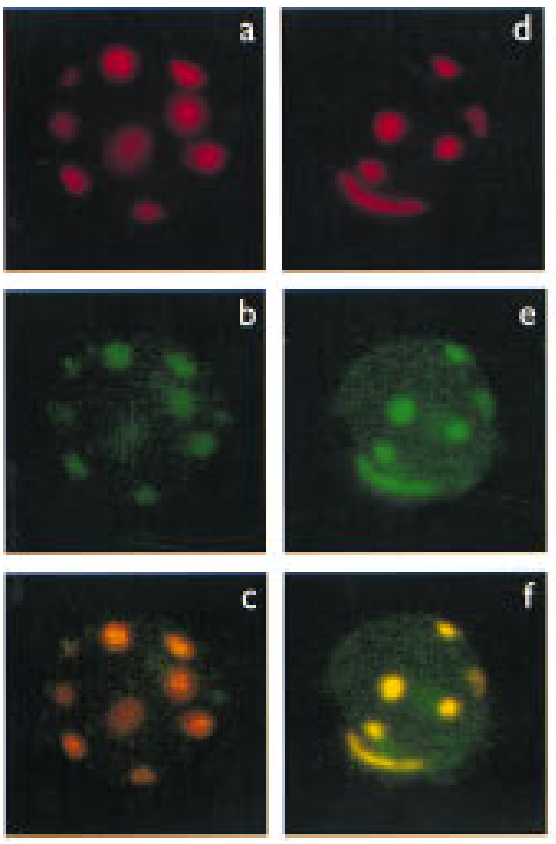
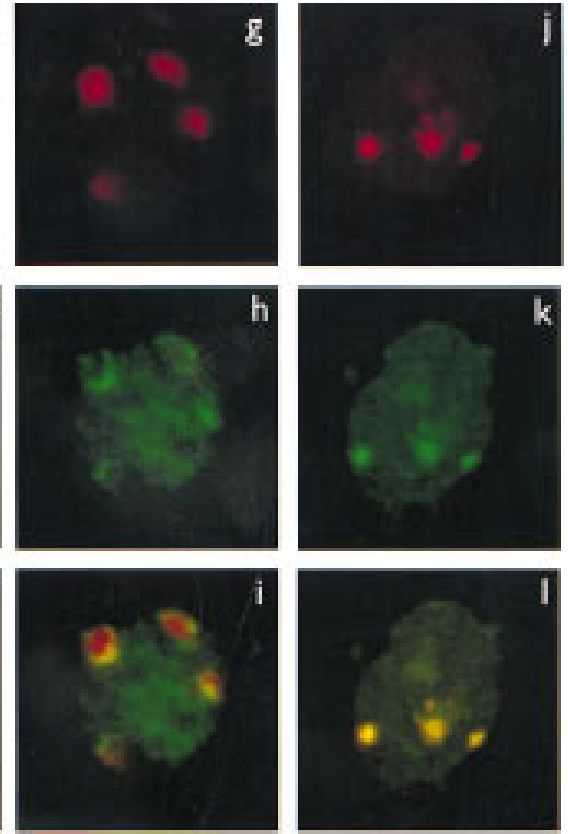

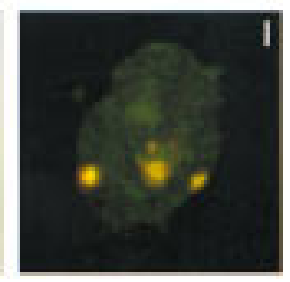

Figure 10. Distribution of Helios and lkaros proteins within the nuclei of $\mathrm{T}$ and $\mathrm{B}$ lymphocytes. Confocal images are shown of single optical sections through the nucleus of representative individual concavalin-A stimulated Iymph node $T$ cells (a,b,c,g,h,i), activated VL3-3M2 T cells $(d, e, f)$, and B3 pre-B cells $(j, k, I)$. The cells were labeled simultaneously with a probe for gamma satellite sequences (red) and specific antisera for Helios (a-f) or Ikaros ( $g-l$ ) (shown in green). The red and green components of costained nuclei (bottom, c,f,i, I) are shown separately in the top (gamma satellite-red $a, d, g, j)$ and middle (p70-green $b, e$, Ikaros-green $h, k$ ) rows. 
and yellow colors. The yellow color observed in costained VL3-3M 2 cells indicates that the intensity of Helios staining is greater than in the lymph node T cells, which yield an orange color. It is worth noting, however, that the intensity of Helios staining in both of these cell types was much weaker than the intensity of Ikaros staining. (The images in Fig. 10 do not reflect the lower abundance of $\mathrm{Helios}$ because different settings were used for the Helios images to enhance detection.) These results are consistent with those in Figure 8, which demonstrate that Helios is much less abundant than Ikaros in T cells. Because the data in Figure 8 demonstrate that Helios is quantitatively associated with a subset of the Ikaros, the most likely interpretation of the confocal results is that the Ikaros-Helios complexes are predominantly localized to the centromeric foci. In contrast, the excess Ikaros that is not associated with Helios appears to be distributed more broadly throughout the nucleoplasm.

Although not easily apparent from the images shown in Figure 10, the similar staining patterns of Helios and gamma satel lite repeats may not represent true col ocalization (i.e., identity of spatial location). Instead, the Helios staining appears to extend slightly beyond the gamma satel lite staining. Preliminary studies of deconvolved images are consistent with this observation (K.E. Brown and A.G. Fisher, unpubl.), suggesting that Helios and gamma satel lites are interlaced rather than spatially identical.

\section{Discussion}

Gene disruption experiments have shown that Ikaros isoforms carry out critical functions during the development of B and T lymphocytes, as well as other hematopoietic cell types (Georgopoulos et al. 1994; Winandy et al. 1995; Wang et al. 1996). Nevertheless, in light of the centromeric heterochromatin localization that has been observed (Brown et al. 1997; Klug et al. 1998), the precise intracellular functions of Ikaros al most certainly will be difficult to elucidate. The finding that Ikaros protein complexes are sufficiently stable to allow their purification by immunoaffinity chromatography provides a means of identifying rel evant Ikaros partners within any given cell type or cell line, information which will be essential for fully understanding Ikaros functions. Our analysis of the complexes within the RLM11 T cell line led to the identification of a new member of the Ikaros family, Helios. The rel evance of the Helios-Ikaros interaction was demonstrated by the quantitative association in the two cell lines examined. The specific functions of Helios and of the Helios-Ikaros complex remain unknown, but the colocalization of Helios-lkaros complexes with gamma satellites suggests that Helios might be a limiting regulatory factor that recruits a subset of the Ikaros within a T cell to centromeric foci.

The function of the Helios-lkaros complexes at the centromeric regions, and the function of the excess Ikaros distributed throughout the nucleus, remains to be elucidated. One hypothesis is that Helios-Ikaros complexes bind to DNA sequence elements within the promoters, enhancers, or silencers of genes that are destined for inactivation. Binding of Helios-Ikaros might result in the recruitment of those genes to the centromeric foci, where they might be assembled into inactive heterochromatin structures. A more extensive discussion of the possible functions for these proteins at centromeric re gions, and a discussion of related studies of Drosophila heterochromatin regulation and position effect variegation, can be found in Brown et al. (1997).

The reason for the broad distribution of I karos in T cell nuclei, relative to its predominant centromeric localization in B cells, also remains unknown. Perhaps, B cells contain a more abundant partner for Ikaros that recruits a larger fraction of the Ikaros pool to the centromeric foci. Alternatively, Ikaros may be capable of localizing to the centromeric regions in $\mathrm{B}$ cells in the absence of a partner. The large pool of Ikaros in T cells that is not localized to the centromeres may simply be excess protein that carries out no specific functions. Alternatively, this pool may carry out one or more critical functions related to the activation or inactivation of specific genes, perhaps acting as a more typical activator or repressor in combination with other transcription factors, coactivators, or corepressors. Although our discussion of Ikaros and Helios has focused on their possible roles in transcriptional regulation, it is important to note that no compelling evidence has been published demonstrating that Ikaros or Helios are actually involved, either directly or indirectly, in transcription. Alternative functions that must be considered are involvement in nuclear structure, DNA synthesis, or mitosis.

The discovery of a T cell-restricted member of the Ikaros family leads to models that might explain some of the phenotypes observed in mice containing I karos gene disruptions. Ikaros ${ }^{-1-}$ mice lack all cells of the B lineages, but exhi bit less severe defects in some of theT cell lineages (see introductory section; Wang et al. 1996) even though I karos normally appears to be expressed in all B and $\mathrm{T}$ cells. Perhaps complete disruption of the Ikaros gene has relatively modest effects on T cell development because Helios compensates for the absence of Ikaros. This hypothesis is supported by the finding that Helios and Ikaros recognize similar DNA sequences. A more severe $T$ cell defect was observed in mice containing a specific disruption of the zinc finger DNA-binding domains of Ikaros; these mice, which retain the capacity to produce smaller Ikaros proteins containing the carboxyterminal protein-protein interaction domain, do not produce any progenitor or mature $\mathrm{T}$ cells (Georgopoulos et al. 1994). The severity of this mutation within the T cell lineage might be due to the fact that the small Ikaros proteins act in a dominant negative manner, sequestering Helios and preventing it from compensating for the loss of Ikaros.

Consistent with the hypothesis that Ikaros and Helios might not simply be transcriptional activators, we have been unable to detect transcriptional activation functions for either protein by standard transient and stable 
transfection assays (B.S. Cobb and K. Hahm, unpubl.). Ikaros proteins contain a domain that functions as a strong transactivation domain when fused to a GAL4 DNA-binding domain (Sun et al. 1996; K. Hahm, L. Trinh, P. Ernst, and S.T. Smale, in prep.). Transactivati on of reporter plasmids has also been reported with the full-length protein (Molnar and Georgopoulos 1994). In our hands, however, we have been unabl e to detect transactivation with either full-length Ikaros or Helios, or a combination of the two, despite efficient expression of the proteins and despite the fact that extracts from those cells contain the expected DNA-binding activities (B.S. Cobb and A.S. M cCarty, unpubl.). Because these results are negative, they can only be substantiated by the demonstration that Ikaros and Helios carry out a different function. It remains possible that Ikaros functions as a activator of some genes through combinatorial interactions, yet is involved in heterochromatin formation on other genes at the centromeric foci. Such a function would be similar to that proposed for the Drosophila Hunchback protein, which contains zinc finger domains that are highly related to those in Ikaros and Helios. Hunchback acts as a si mpl e activator during embryogenesis and also has been proposed to establish silencing complexes in Drosophila by recruiting Polycomb-group proteins (Zhang and Bienz 1992; Poux et al. 1996).

The stoichiometry and structure of the complexes observed by gel filtration chromatography and other techniques remain unknown. Some techniques strongly suggest that Ikaros complexes are composed of highly stable dimers. Other techniques suggest that the compl exes are multimeric (see Results). Additional experiments will be needed to clarify these results and, if multimeric complexes are indeed present in cell extracts, to determine whether these complexes are the functional species in vivo. On the basis of all the data that has been obtained, our working model is that the complexes contain highly stable dimers that associate into multimers.

The homogeneous nature of the Ikaros compl exes that contain Helios, as judged by gel filtration chromatography, is particularly intriguing. Because Helios appears to interact indiscriminately with the various Ikaros isoforms following overexpression in 293T cells, it is not clear why Helios would elute in a sharper peak than Ikaros. A pparently, within RLm11 cells, the interactions are not as indiscriminate as predicted. Perhaps, the smaller Ikaros complexes observed by gel filtration are partially assembled complexes, with Helios the final component added to the complex. Whatever the reason for the homogeneity of the Helios complexes, this distinction from Ikaros is likely to rely on domains other than the zinc finger domains, since the zinc fingers are extremely well conserved.

\section{Materials and methods}

\section{Plasmid DNAs}

Mammalian expression plasmids for Ikaros isoforms I, III, V, and VI were prepared in the pcDNAlneo vector (InVitrogen).
CDN As for these isoforms in the pSP72 vector (see $\mathrm{Hahm}$ et al. 1994) were excised with Bglll and Xhol and inserted into pcDNA Ineo cleaved with BamHI and Xhol. Plasmids for expression in Escherichia coli of fusion proteins between Helios $A$ and GST were prepared for antibody preparation and DN A-binding studies. Fragments encoding Helios A amino acids 1-109 (for antibody preparation) and 1-292 (for DN A-binding studies) were generated by PCR from the full-length Helios A CDNA with a primer spanning the amino-terminal coding region, 5'GATAGATCTATGGAAACAGACGCAATTGA-3', and the reverse primers 5'-GATGAATTCGTCCATCATATGAGACTGCATCAG-3' or 5'-GATGAATTCGCCTTGAAGGTCCTGGACTTT-3', respectively. The 327- and 876-bp PCR products, respectively, were cleaved with BgllI and EcoRI and inserted into pGEX 2T (Pharmacia) cleaved with BamHI and EcoRI.

The mammalian expression plasmid for FLAG-tagged Helios A was prepared by amplifying the protein-coding sequence with the following PCR primers: 5'-GATAGATCTATGGAAACAGACGCAATTGA-3' and 5'-GATGAATTCCTAGTGGAATGTGTGCTCCCC-3'. The PCR product was cleaved with BgllI and EcoRI and inserted into pSP72 cleaved with the same enzymes. The following FLAG-encoding ol igonucl eoti de and its complement were then annealed, cleaved with Bglll and BamHI, and inserted into the BgllI-cleaved plasmid: 5'-GATAGATCTACCATGGACTACAAGGACGACGATGACAAGGGATCCGAT-3'. Finally, the entire coding sequence was transferred to the pcDNA3 expression vector (InVitrogen) following cleavage of the PSP72 plasmid with Bglll and Xhol and the vector with BamHI and Xhol.

\section{Cell culture and transient transfections}

RLm11, VL3-3M2, and other cell lines were maintained as described previously (Groves et al. 1995; Ernst et al. 1996). Transient transfections of 293T cells were performed by a calcium phosphate coprecipitation method (Ausubel et al. 1989) with the amounts of plasmid DN A indicated in the figure legends.

\section{Antibodies}

Ikaros antisera were generated against GST -fusi on proteins containing amino-terminal amino acids 1-80 of isoform I and carboxy-terminal amino acids 54-286 of isoform I. Helios antisera were generated against a GST fusion protein containing aminoterminal amino acids 1-109. These fusion proteins were purified by glutathione-Sepharose chromatography and used to immunize rabbits as described previously ( $\mathrm{Hahm}$ et al. 1994). The Elf-1 antiserum was described previously (Ernst et al. 1996). IgGs from preimmune and immune sera were purified by protein A-Sepharose (Pharmacia) chromatography as described by Harlow and Lane (1988).

\section{Gel filtration and DNA-affinity chromatography}

Gel filtration chromatography was performed with prepacked Superdex 200 and Superose 6 FPLC columns (Pharmacia). Approximately $1 \mathrm{mg}$ of RLm11 nuclear extract in a volume of 500 $\mu \mathrm{l}$ was applied to the column in HGED.45 buffer (20 mM HEPES at pH 7.9, 20\% glycerol, $0.2 \mathrm{~mm}$ EDTA, $1 \mathrm{~mm}$ dithiothreitol, 0.1 $\mathrm{mM}$ PMSF, and $0.45 \mathrm{M} \mathrm{KCl}$ ) containing $0.015 \% \mathrm{NP}-40$. Some experiments were performed with $0.15 \mathrm{M} \mathrm{KCl}$ and without NP40. Fractions $(500 \mu \mathrm{l})$ were collected and $45 \mu \mathrm{l}$ of each was analyzed by immunoblot. M olecular size markers were thyroglobulin (669 kD), ferritin (440 kD), catal ase (232 kD), and al bumin (67 kD) (Pharmacia).

Sequence-specific DNA-affinity chromatography was per- 
formed with $0.5 \mathrm{ml}$ of resin containing covalently linked multimers of the TdT D sequence as described previously (Hahm et al. 1994).

\section{Purification of Ikaros complexes and peptide sequencing}

Immunoaffinity columns were prepared by covalent coupling of antibodies to protein A-Sepharose (Pharmacia) by the method described in Harlow and Lane (1988). Ikaros complexes were purified by the following method. RLm11 nuclear extracts (200 $\mathrm{mg}$ ) in buffer D (20 mM HEPES at pH 7.9, 20\% glycerol, $0.2 \mathrm{~mm}$ EDTA, $1 \mathrm{~mm}$ dithiothreitol, $0.1 \mathrm{~mm}$ PMSF, $0.42 \mathrm{M} \mathrm{KCl}$ ) were applied to a precolumn containing $500 \mu$ l of unmodified protein A-Sepharose, with the eluate flowing directly onto the bed of a 4-ml immunoaffinity column. The extract was passed through both columns three times. The immunoaffinity column was then washed with 10 column volumes of HGED buffer $(20 \mathrm{~mm}$ HEPES at pH 7.9, 20\% glycerol, $1 \mathrm{~mm}$ EDTA, $1 \mathrm{~mm}$ DTT, 0.1 $\mathrm{mm}$ PMSF) containing $0.45 \mathrm{M} \mathrm{KCl}$ and $1 \mathrm{M} \mathrm{KCl}$. In some experiments, the column was al so washed with HGED buffer containing no $\mathrm{KCl}$. Bound proteins were eluted in 1-ml fractions into tubes containing $20 \mu \mathrm{l}$ of $2 \mathrm{M}$ Tris- $\mathrm{HCl}(\mathrm{pH}$ 6.8) with $100 \mathrm{~mm}$ trimethyl ethanolamine ( $\mathrm{pH}$ 11.0). Fractions were analyzed by SDS-PAGE followed by silver staining.

To isolate the 70-kD protein for microsequencing, appropriate fractions from the $\mathrm{pH} 11.0$ elution were pooled. After three runs of a 5-ml affinity column, $10 \mu \mathrm{g}$ of the $70-\mathrm{kD}$ protein was obtained. The pool ed proteins were preci pitated by $20 \%$ trichloroacetic acid (Fisher), separated by SDS-PAGE, transferred to PVDF membrane (Biorad), and stained with Ponceau $\mathrm{S}$ as described previously (Hahm et al. 1994). The 70-kD band was excised and subjected to endopetidase $C$ digestion followed by peptide sequencing as described (Fernandez et al. 1994).

\section{Isolation of Helios CDNAS}

To isolate the Helios gene, first strand CDNA was generated from RLm11 mRNA and used for PCR with the following degenerate primer pairs designed from the two peptide sequences; 5'-GATGAATTCCA (A/G)GA(A/G)CC (A/C/G/T)AT(T/C)A TGGA(C/T)AA(C/T)AA-3', 5'-GATGAATTCTT(C/T)TC(A/ G)TA(A/C/T)GT(C/T)AG(A/G)TTCAT-3'. A 216-bp PCR product was isolated and inserted into pSP72 (Promega) digested with BgllI and EcoRI. The sequence of the insert was determined and found to contain codons encoding the amino acids within the two original peptides that were not included in the PCR primers, confirming that the fragment was derived from the correct gene. To isol ate a full-length cDN A, the 216-bp fragment was radiolabeled and used to screen a newborn thymus cDN A library (Stratagene) as previously described ( $\mathrm{H}$ ahm et al . 1994). The resulting full-length CDNA encodes the Helios A protein. The Helios B CDNA was isolated by RT-PCR with the following primers flanking the amino-terminal zinc finger domain.

Plasmids encoding Helios A-GST fusion proteins were introduced into the SCS-1 strain of E. coli (Stratagene). Fusion proteins were then induced, purified and stored at $-80^{\circ} \mathrm{C}$ as de scribed previously (Hahm et al. 1994).

\section{Immunoprecipitation and immunoblot analyses}

293T cell immunopreci pitation assays were performed from cytoplasmic or nuclear extracts with the following method. First, cytoplasmic and nuclear extracts were prepared from four 100$\mathrm{mm}$ plates of transfected cells by Dounce homogenization as described by Lo et al. (1991). N uclear extracts $(400 \mu \mathrm{g})$ were incubated with 3-6 $\mu$ g of FLAG M 2 monoclonal antibody (Kodak IBI) for 2-4 hr at $4^{\circ} \mathrm{C}$, foll owed by centrifugation for $10 \mathrm{~min}$. Supernatants were transferred to a new tube and mixed with 40 $\mu l$ of protein A-Sepharose (Pharmacia). The slurry was incubated for $1 \mathrm{hr}$ at $4^{\circ} \mathrm{C}$. After brief centrifugation, pellets were washed 5 times with buffer containing $10 \mathrm{~mm}$ HEPES ( $\mathrm{pH}$ 7.9), $0.45 \mathrm{M} \mathrm{KCl}, 1 \mathrm{~mm}$ EDTA, 0.015\% N P-40, 10\% glycerin, and 1 $\mathrm{mm}$ dithiothreitol. The washed pellets were analyzed by SDSPAGE followed by immunoblot as described previously (Hahm et al. 1994).

The quantitative immunopreci pitations were performed with $100 \mu \mathrm{l}$ of RLm11 $(500 \mu \mathrm{g})$ nuclear extract or $200 \mu \mathrm{l}$ of VL3-3M 2 $(1.2 \mathrm{mg})$ nuclear extract. The extract was mixed with $167 \mu \mathrm{l}$ of a buffer containing $100 \mathrm{~mm} \mathrm{NaCl}, 20 \mathrm{~mm}$ Tris (pH 8), and $0.5 \%$ N P-40. To this mixture was added the indicated amount of IgG (against the amino terminus of either Ikaros or Helios), which was diluted to $33 \mu \mathrm{l}$ with PBS. Binding proceeded for $1 \mathrm{hr}$ on ice after which $100 \mu$ l of a $50 \%$ slurry of protein A-Sepharose was added. The mixture was incubated for an additional hour at $4^{\circ} \mathrm{C}$ on a rocker. The resin was pelleted by brief centrifugation and the supernatants were transferred to a new tube. The pellets were washed four times with the above buffer. The immune complexes and a constant proportion of the supernatants were analyzed by SDS-PAGE, followed by immunoblot analysis with antisera against the carboxyl terminus of Ikaros or the aminoterminus of Helios.

\section{Binding-site selection analysis and gel mobility shift assays}

Binding-site selection assays were performed as described by Zweidler-M cKay et al. (1996). The double-stranded ol igonucleotide containing random sequences was generated from the following 66-nucleotide fragment: 5'-GGTAGAATTCAACTGCCATCTAGGN N N N N N N N N N N N N N N N NACACCGAG TCCAGTGGATCCTACG-3'. The complementary strand was generated by anneal ing the following primer and extending with the E. coli DNA polymerase Klenow fragment: 5'-CGTAGGATCCACTGGACTCGGTG-3'. The DNA fragments containing random sequences were incubated with the recombinant GST-Helios A fusion protein. Bound DN A molecules were separated from unbouind molecules by incubation with GSTSepharose, followed by centrifugation (Zweidler-McKay et al. 1996). Bound DNA molecules were eluted and amplified by PCR with the above 23-mer and the following reverse primer: 5'-GGTAGAATTCAACTGCCA-3'. After four binding cycles, the final PCR products were digested with EcoRI and HindIII and inserted into pSP72 (Promega). Thirty-two clones were analyzed by sequencing.

For gel mobility shift analysis, the IkBS1 probe was prepared from a plasmid containing the foll lowing ol igonucl eotide and its complement inserted into the BamHI site of pSP72: 5'GATCTTCAGCTTTTGGGAATCTCCTGTCAG-3'. The Hs BS1 and Hs BS2 probes were prepared from plasmids containing the following oligonucleotides and their complements inserted into the HindlII and EcoRI sites of pSP72: Hs BS1, 5'-CGTGTATCCATAGGGAAAATTATCCTAGAT-3'; Hs BS2, 5'GATCTCGTGTGATTTTCCTAATGAGAATCCTAGATG-3'. The TdT D and D' probes were described previously ( $\mathrm{Hahm}$ et al. 1994). Radiolabeled probes were prepared as described previously (Ernst et al. 1993) following cleavage with Hindlll and EcoRI. The SP72 control probe was cleaved with BglII and Xhol. Binding reactions were performed as described by Lo et al. (1991). Samples were analyzed as described in Ernst et al . (1993).

Northern blot analysis

RNAs from cell lines and tissues were prepared by a guanidine 
thiocyanate centrifugation method (Ausubel et al. 1989). Tissues used to generate RNAs were isolated from 1-month-old Bal b/c mice. N orthern blot probes were prepared from a 216-bp p70 fragment encoding amino acids 221-292, and were label ed using the Prime-lt Kit (Stratagene).

RT-PCR of Helios in thymocyte subsets and in splenic myeloid and $B$ cell populations

Thymocyte subsets (CD-3-CD $-4{ }^{-} C D-8^{-}, C D-3^{+} C D-4^{+} C D-8^{+}$, and $C D-3^{+} C D-4^{+} C D-8 \rightarrow$ were sorted by use of the following combination of fluorochromes: CD-3 $3^{\mathrm{PE}}, \mathrm{CD}-4^{\mathrm{FITC}}$, and CD$8^{\mathrm{APC}}$. Splenic myeloid cells were sorted as $\mathrm{Gr}-\mathrm{1}^{\mathrm{HI}} \mathrm{Mac}-1^{+}$and splenic B cells were isolated as $\mathrm{B} 220^{+}$cells. Each cell population was sorted once and then cl one-sorted directly into 0.2-ml tubes containing $20 \mu \mathrm{l}$ of RT lysis buffer [ $5 \times$ first strand buffer (GibcoBRL), 10 mM DTT, 2\% Triton X-100, 0.01\% BSA, 0.2 mm spermidine, 0.4 units of RN asin (Promega), 100 ng of RT primer, 0.5 $\mathrm{mM}$ each dNTP]. Reactions were initiated by adding $1 \mu \mathrm{l}$ of M MLV reverse transcriptase. Reactions were incubated for 75 $\min$ at $37^{\circ} \mathrm{C}$. A bout $10 \%-15 \%$ of the CDN A reaction was used as a template for 35 cycles of PCR with the outside primers listed below (PCR conditions: $94^{\circ} \mathrm{C}$ for $30 \mathrm{sec}, 55^{\circ} \mathrm{C}$ for $30 \mathrm{sec}$, and $72^{\circ} \mathrm{C}$ for $30 \mathrm{sec}$ ). Five percent of the first PCR reaction was used as template for a second round of 35 cycles with the inside primer set and the same PCR conditions described above. Products were resolved on a 1.5\% agarose gel and then blotted for Southern analysis with an oligonucleotide (Helios probe) complementary to an exon located just upstream of the first zinc finger exon in Helios. Control reactions received sorted cells but no reverse transcriptase. At least four large introns occur between the exon sequences being amplified by the inside primer set.

The following oligonucleotides used for the RT-PCR and Southern blots are written in a 5' to $3^{\prime}$ orientation: RT primer, GCATTGTTGATGGCTTGGTC; outside primers, GGGGAACA CGCCAATATGGC ( 5 ' end) and GCATCAGCTCAGCCTCCTTC ( 3 ' end); inside primers, CCAATGGACAGCACGCCTCG (5' end) and ATATCTGGGTAGCTGAATCGC ( $3^{\prime}$ end); p70 probe, CCCTGAGCCGTGAGGATGAG.

\section{Confocal microscopy}

Lymph node $T$ cells were prepared as follows: Lymph nodes were removed from a Balb/c mouse and minced in sterile medium to yield a single cell suspension. After washing, cells were resuspended at $2.5 \times 10^{6} / \mathrm{ml}$ and cultured at $37^{\circ} \mathrm{C}$ in AM DM medium containing $10 \%$ FCS, antibiotics, concanavalin A (5 $\mu \mathrm{g} / \mathrm{ml})$ and IL-2 $(20 \mathrm{U} / \mathrm{ml})$. After $36 \mathrm{hr}$, live cells were enriched by ficoll separation and cultured for a further $24 \mathrm{hr}$ in $1 \mathrm{M} \mathrm{DM}$ containing $10 \% \mathrm{FCS}$ and IL-2 $(20 \mathrm{U} / \mathrm{ml})$ at $37^{\circ} \mathrm{C}$. VL3-3M 2 cells were activated with PMA $(10 \mathrm{ng} / \mathrm{ml})$ and ionomycin $(250 \mathrm{ng} /$ $\mathrm{ml}$ ) as described previously (Groves et al. 1995). B3 cells, the gamma satellite probe, and the immunofish protocol were described previously (Brown et al. 1997).

\section{Acknowledgments}

K.H. and R.L. were supported by U.S. Public Health Service (U.S. PHS) Training Grants GM-07104 and GM-08042, respectively. C.A.K. was a fellow of the Irvington Institute, I.L.W. was supported by grants from the National Cancer Institute (CA 42551) and from SyStemix/Sandoz, A.G.F. was supported by the M edical Research Council, UK, and S.T.S. was supported by
U.S. PHS grant DK43726. S.T.S. is an Associate Investigator with the Howard Hughes Medical Institute.

The publication costs of this article were defrayed in part by payment of page charges. This article must therefore be hereby marked "advertisement" in accordance with 18 USC section 1734 solely to indicate this fact.

\section{References}

Ausubel, F.M., R. Brent, R.E. Kingston, D.D. Moore, J.G. Seidman, J.A. Smith, and K. Struhl. 1989. Current protocols in molecular biology. John Wiley, N ew York, NY.

Babichuk, C.K., B.L. Duggan, and R.C. Bleackley. 1996. In vivo regulation of murine granzyme $B$ gene transcription in activated primary T cells. J. Biol. Chem. 271: 16485-16493.

Brown, K.E., S.S. Guest, S.T. Smale, K. Hahm, M. Merkenschlager, and A.G. Fisher. 1997. Association of transcriptionally silent genes with Ikaros complexes at centromeric heterochromatin. Cell 91: 845-854.

Clevers, H.C. and R. Grosschedl. 1996. Transcriptional control of Iymphoid devel opment: Lessons from gene targeting. Immunol. Today 17: 336-343.

Clevers, H.C., M.A. Oosterwegel, and K. Georgopoulos. 1993. Transcription factors in early $\mathrm{T}$-cell devel opment. Immunol. Today 14: 591-596.

Davis, J.N. and M.F. Roussel. 1996. Cloning and expression of the murine Elf-1 cDN A. Gene 171: 265-269.

Ernst, P. and S.T. Smale. 1995. Combinatorial regulation of transcription II: The immunoglobulin $\mu$ heavy chain gene. Immunity 2: 427-438.

Ernst, P., K. Hahm, and S.T. Smale. 1993. Both LyF-1 and an Ets protein interact with a critical promoter el ement in the murine terminal transferase gene. Mol. Cell. Biol. 13: 2982-2992.

Ernst, P., K. Hahm, L. Trinh, J.N. Davis, M.F. Roussel, C.W. Turck, and S.T. Smale. 1996. A potential role for Elf-1 in terminal transferase gene regulation. Mol. Cell. Biol. 16: $6121-6131$.

Fernandez, J., L. Andrews, and S.M. Mische. 1994. An improved procedure for enzymatic digestion of polyvinylidene difluoride-bound proteins for internal sequence analysis. Annal. Biochem. 218: 112.

Georgopoulos, K. 1997. Transcription factors required for lymphoid lineage commitment. Curr. O pin. Immun. 9: 222-227.

Georgopoulos, K., D.D. Moore, and B. Derfler. 1992. Ikaros, an early lymphoid-specific transcription factor and a putative mediator for T cell commitment. Science 258: 808-812.

Georgopoulos, K., M. Bigby, J.-H. Wang, A. Molnar, P. Wu, S. Winandy, and A. Sharpe. 1994. The Ikaros gene is required for the development of all lymphoid lineages. Cell 79: 143156.

Georgopoulos, K., S. Winandy, and N. A vitahl. 1997. The role of the Ikaros gene in lymphocyte development and homeostasis. Annu. Rev. Immunol. 15: 155-176.

Groves, T., P. Katis, Z. Madden, K. Manickam, D. Ramsden, G. Wu, and C.J. Guidos. 1995. In vitro maturation of clonal CD4+CD8+ cell lines in response to TCR engagement. J. Immunol. 154: 5011-5022.

Haag, F.A., G. Kuhlenbaumer, F. Koch-N olte, E. Wingender, and H.G. Thiele. 1996. Structure of the gene encoding the rat T cell ecto-ADP-ribosyltransferase RT6. J. Immunol. 157: 2022-2030.

Hagman, J. and R. Grosschedl. 1994. Regulation of gene expression at early stages of B-cell differentiation. Curr. O pin. Immunol. 6: 222-230. 
Hahm, K., P. Ernst, K. Lo, G. Kim, C. Turck, and S.T. Smale. 1994. The lymphoid transcription factor LyF-1 is encoded by a specific, alternatively spliced mRNA derived from the lkaros gene. Mol. Cell. Biol. 14: 7111-7123.

Harlow, E. and D. Lane. 1988. Antibodies: A laboratory manual. Cold Spring Harbor Laboratory, Cold Spring Harbor, NY.

Ikuda, K., N. Uchida, J. Friedman, and I.L. Weissman. 1992. Lymphocyte development from stem cells. Annu. Rev. Immunol. 10: 759-783.

Klug, C.A., S.J. M orrision, M. Masek, K. Hahm, S.T. Smale, and I.L. Weissman. 1998. Hematopoietic stem cells and lymphoid progenitors express different Ikaros isoforms and Ikaros is localized to heterochromatin in immature lymphocytes. Proc. Natl. Acad. Sci. 95: 657-662.

Lo, K., N.R. Landau, and S.T. Smale. 1991. LyF-1, a transcriptional regulator that interacts with a novel class of promoters for Iymphocyte-specific genes. Mol. Cell. Biol. 11: 52295243.

Molnar, A. and K. Georgopoulos. 1994. The lkaros gene encodes a family of functionally diverse zinc finger DNA-binding proteins. Mol. Cell. Biol. 14: 8292-8303.

Molnar, A., P. Wu, D.A. Largespada, A. Vortkamp, S. Scherer, N.G. Copeland, N.A. Jenkins, G. Bruns, and K. GeorgopouIos. 1996. The Ikaros gene encodes a family of lymphocyterestricted zinc finger DNA binding proteins, highly conserved in human and mouse. J. I mmunol. 156: 585-592.

Morgan, B., L. Sun, N. Avitahl, K. Andrikopoulos, T. Ikeda, E. Gonzal es, P. Wu, S. N eben, and K. Georgopoulos. 1997. Aiolos, a lymphoid restricted transcription factor that interacts with Ikaros to regulate lymphocyte differentiation. EMBO J. 16: 2004-2013.

M orrison, S.J., N . Uchida, and I.L. Weissman. 1995. The biology of hematopoietic stem cells. Annu. Rev. Cell. Devel. Biol. 11: 35-71.

Omori, S.A. and R. Wall. 1993. Multiple motifs regulate the B-cell-specific promoter of the B29 gene. Proc. Natl. Acad. Sci. 90: 11723-11727.

Orkin, S.H. 1995. Hematopoiesis: How does it happen? Curr. Opin. Cell Biol. 7: 870-877.

Poux, S., C. Kostic, and V. Pirrotta. 1996. Hunchback-independent silencing of the late UBX enhancers by a polycomb group response element. EMBO J. 15: 4713-4722.

Santee, S.M. and L.B. Owen-Schaub. 1996. Human tumor necrosis factor receptor p75/80 (CD120b) gene structure and promoter characterization. J. Biol. Chem. 271: 21151-21159.

Shortman, K. and L. Wu. 1996. Early T Iymphocyte progenitors. Annu. Rev. Immunol. 14: 29-47.

Singh, H. 1996. Gene targeting reveals a hierarchy of transcription factors regulating specification of lymphoid cell fates. Curr. Opin. Immunol. 8: 160-165.

Sun, L., A. Liu, and K. Georgopoulos. 1996. Zinc finger-mediated protein interactions modulate lkaros activity, a molecuIar control of Iymphocyte development. EMBO J. 15: 53585369.

Ting, C.N., M.C. Olson, K.P. Barton, and J.M. Leiden. 1996. Transcription factor GATA-3 is required for devel opment of the T-cell lineage. Nature 384: 474-478.

Tsai, S., S. Bartelmez, E. Sitnicka, and S. Collins. 1994. Lymphohematopoietic progenitors immortalized by a retroviral vector harboring a dominant-negative retinoic acid receptor can recapitulate lymphoid, myeloid, and erythroid devel opment. Genes \& Dev. 8: 2831-2841.

Wang, J., H. Walker, Q. Lin, N. Jenkins, N.G. Copeland, T. Watanabe, P.D. Burrows, and M.D. Cooper. 1996. The mouse BP-1 gene: Structure, chromosomal localization, and regulation of expression by type I interferons and interleukin-7. Genomics 33: 167-176.

Wang, J.-H., A. N ichogiannopoulou, L. Wu, L. Sun, A.H. Sharpe, M. Bigby, and K. Georgopoulos. 1996. Sel ective defects in the development of the fetal and adult lymphoid system in mice with an Ikaros null mutation. Immunity 5: 537-549.

Wargnier, A., S. Legros-M aida, R. Bossel ut, J.F. Bourge, C. Lafaurie, C.J. Ghysdael, M. Sasportes, and P. Paul. 1995. Identification of human granzyme $B$ promoter regulatory el ements interacting with activated T-cell-specific proteins: Implication of Ikaros and CBF binding sites in promoter activation. Proc. Natl. Acad. Sci. 92: 6930-6934.

Willerford, D.M., W. Swat, and F.W. Alt. 1996. Developmental regulation of $\mathrm{V}(\mathrm{D})$ ) recombination and lymphocyte differentiation. Curr. Opin. Genet. Dev. 6: 603-609.

Winandy, S., P. Wu, and K. Georgopoulos. 1995. A dominant mutation in the Ikaros gene leads to rapid development of leukemia and lymphoma. Cell 83: 289-299.

Zhang, C.C. and M. Bienz. 1992. Segmental determination in Drosophila conferred by hunchback (hb) a repressor of the homeotic gen Ultrabithorax (Ubx). Proc. Natl. Acad. Sci. 89: 7511-7515.

Zweidler-M cKay, P.A., H.L. Grimes, M.M. Flubacher, and P.N . Tsichlis. 1996. Gfi-1 encodes a nuclear zinc finger protein that binds DNA and functions as a transcription repressor. Mol. Cell. Biol. 16: 4024-4034. 


\title{
Errata
}

Genes \& Development 11: 3265-3276 (1997)

The Xenopus Brachyury promoter is activated by FGF and low concentrations of activin and suppressed by high concentrations of activin and by paired-type homeodomain proteins

Branko V. Latinkić, M uriel U mbhauer, Kathy A. N eal, Walter Lerchner, James C. Smith, and Vincent Cunliffe

The first author's name was spelled incorrectly in this article. It is correct here.

Genes \& Development 12(6) March 15, 1998

The cover headline and caption for this issue were incorrect. The headl ine should read:

Regulation of the cell division protein FtsZ in Caulobacter.

The correct caption is printed bel ow.

Cover Caulobacter crescentus and the cell division initiation protein FtsZ through the cell cycle. Shown are electron micrographs of Caulobacter (top) and immunofluorescence analysis of FtsZ (bottom) at different stages through the cell cycle. The cell cycle initiates with a swarmer cell (left) that contains a single polar flagel lum (wavy line), which differentiates into a stalked cell (third from left) by shedding the flagellum and synthesizing a stal $k$ at the same pole. The predivisional cell (fourth from left) contains a single flagellum synthesized at the pole opposite the stalk. Cell division produces a swarmer cell and stalk cell (right). The replication-competent stalk cell contains FtsZ, whereas the replication-incompetent swarmer cell lacks FtsZ. (For details, see Kelly et al., p. 880.)

Genes \& Development 12: 782-796 (1998)

\author{
Helios, a T cell-restricted Ikaros family member that quantitatively associates with I karos at centromeric \\ heterochromatin \\ Kyungmin Hahm, Bradley S. Cobb, Aaron S. McCarty, Karen E. Brown, Christopher A. Klug, Robert Lee, \\ Koichi Akashi, Irving L. Weissman, A manda G. Fisher, and Stephen T. Smale
}

The name of Irving L. Weissman was spelled incorrectly in the Table of Contents of this issue. It is correct here.

\section{Genes \& Development 12(7)}

The cover headline and caption for this issue were incorrect. The headl ine should read: Role of CBP in C. elegans embryonic differentiation

The correct caption is printed below.

Cover Expression and phenotypic analysis of CBP-1 in Caenorhabditis elegans. Shown are $\mathrm{N}$ omarski images of wild-type (top left) and cbp-I mutant (top right) embryos. The mutant embryo produces many small cells and shows no evidence of mesodermal, endodermal, or hypodermal tissue organization. The small cells are reminiscent of neuronal cells, and immunostaining with antibodies against UNC-86, a neuronal differentiaton-specific protein, of wild-type (bottom left) and cbp-I (bottom right) reveals an increase in the number of neuronal precursors in mutant embryos. (For details, see Shi and Mello, p. 943). 


\section{Erratum}

Genes \& Development 12: 304-315 (1998)

inscuteable and numb mediate asymmetric muscle progenitor cell divisions during $D$ rosophila myogenesis Ana Carmena, Bernadette Murugasu-Oei, Devi Menon, Fernando Jiménez, and William Chia

Figure 6 of this article should have appeared in color. The correct figure and legend appear bel ow.

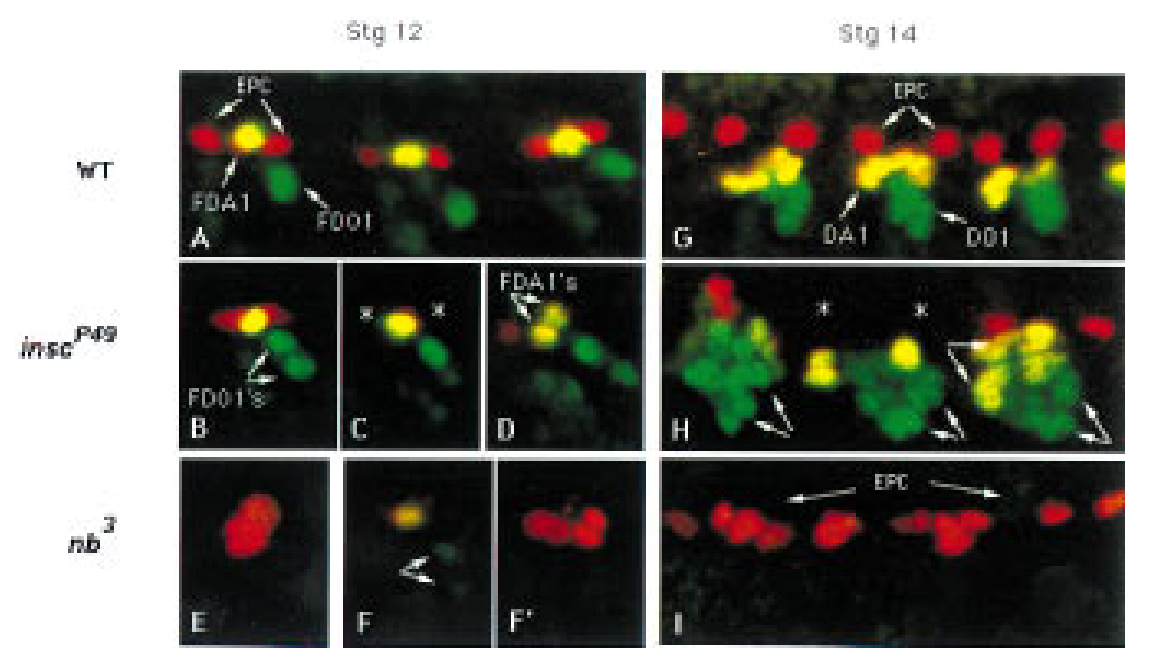

Figure 6. The fate of the progeny from $\mathrm{P} 2$, P15, and P17 progenitors in wild-type, insc $^{\text {P49, }}$, and numb ${ }^{3}$ embryos. Embryos were double stained for Eve (red) and $\mathrm{Kr}$ (green). Stage $12\left(A-F^{\prime}\right)$ and stage $14(G-I)$ wild-type $(A, G)$, insc ${ }^{P 49}(B-D, H)$, and $n b^{3}$ $\left(E-F^{\prime}, I\right)$ embryos are shown. (A) Three consecutive wild-type hemisegments at midto late-stage 12. At this stage, the two EPC (red) are already present. The $\mathrm{Kr}^{+} \mathrm{Eve}^{+}$ FDA 1 (yellow) and the $\mathrm{Kr}^{+} \mathrm{FDO} 1$ (green) are also evident. (B-D) In insc ${ }^{\mathrm{P} 49}$ embryos, the incomplete expressivity of the mutant phenotype is evident in different hemisegments and is characterized by duplication of FDO1 (B), loss of the two EPC $(C, *)$, and duplication of the FDA 1 (D). (E-F') The opposite phenotype is found in $\mathrm{nb}^{3}$ embryos: Two FEPCs are detected at early stage 12,

which are enlarging to divide (E), and no putative FDA 1 and FDO 1 are detected that express Eve and/or Kr. At mid-stage 12, extra EPCs are detected $\left(F^{\prime}\right)$. $\left(F, F^{\prime}\right)$ Two different focal planes of the same mutant hemisegment at mid-stage 12. (F) The FDA 1 (yellow cells) is losing Eve and $\mathrm{Kr}$ expression; likewise, $\mathrm{Kr}$ expression is decaying in both siblings produced by division of P17 (arrows). (G) The characteristic pattern of EPC and precursors of DA 1 and DOI in a wild-type embryo at stage 14. (H) In an insc ${ }^{\text {P49 }}$ embryo, Ioss of EPC $\left(^{*}\right)$ and duplication of the precursors of muscles DA 1 (yellow syncytia, arrows) and DO1 (green syncytia, arrows) are evident. (I) The opposite phenotype is observed in a $\mathrm{nb}^{3}$ embryo; extra EPCs and the absence of DA1 and DO1 muscle precursors. 


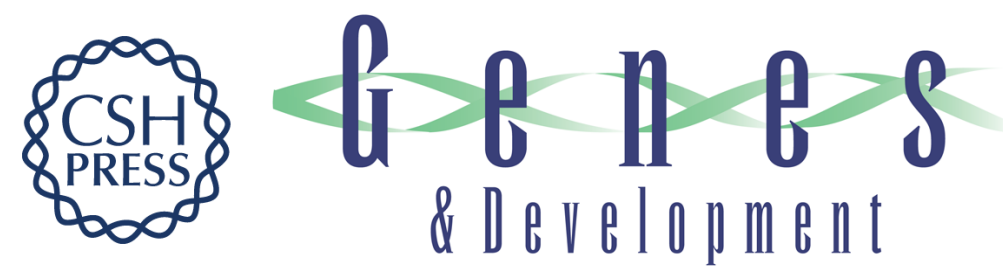

\section{Helios, a T cell-restricted Ikaros family member that quantitatively associates with Ikaros at centromeric heterochromatin}

Kyungmin Hahm, Bradley S. Cobb, Aaron S. McCarty, et al.

Genes Dev. 1998, 12:

Related Content Errata for vol. 12, p. 782

Genes Dev. April , 1998 12: 1240

References This article cites 40 articles, 18 of which can be accessed free at: http://genesdev.cshlp.org/content/12/6/782.full.html\#ref-list-1

Articles cited in:

http://genesdev.cshlp.org/content/12/6/782.full.htmI\#related-urls

License

Email Alerting Receive free email alerts when new articles cite this article - sign up in the box at the top

Service right corner of the article or click here.

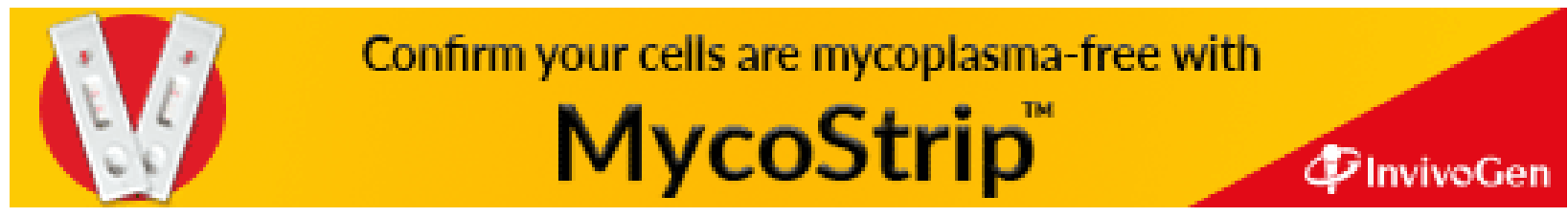

